\title{
EL PALEOLÍTICO EN EL VALLE MEDIO DEL EBRO: UNA "REVISTA DE PRENSA" EN EL CAMBIO DE MILENIO
}

\section{THE PALAEOLITHIC PERIOD IN THE EBRO VALLEY: A SYNTHESIS}

\author{
por
}

\author{
PILAR UTRILLA MIRANDA
}

RESUMEN Se pasa revisión al estudio del Paleolítico en el año 2000, con aportaciones nuevas para el Paleolítico Inferior en Teruel (elefantes de Cuesta de la Bajada) y La Rioja (series del Najerilla). En el Paleolítico Medio se reexamina el valor de las facies musterienses para conocer la funcionalidad de los asentamientos, analizando la cueva de Gabasa como modelo de cazadero (compartido con carnívoros) y la de Peña Miel como modelo de hábitat permanente (con aprovechamiento extremo de los huesos). Se plantea también la validez del término "Frontera del Ebro" en el 40.000 ya que existen niveles musterienses tardíos al Norte de este río, del mismo modo que se repasan los yacimientos del Paleolítico Superior Inicial del Valle del Ebro (Peña Miel en Rioja, abrigo del Ángel en Teruel; Zatoya, Mugarduia y Alquerdi en Navarra). En el Magdaleniense se analiza la organización microespacial del nivel "e" de la cueva de Abauntz con los últimos datos de la segunda sala y se pasa revista a la extensión de esta cultura por el valle del Ebro desde el Prepirineo (Chaves, Forcas, Peña 14, Parco, Montlleó) hasta territorios antes desconocidos y que marcan la extensión hacia la Meseta a través del valle del Henar (Peña del Diablo, abrigos Vergara y Alexandre) y el piedemonte del Moncayo (cueva Bolichera). La ruta hacia Levante quedaría marcada por los yacimientos de Guadalope y Mijares (abrigo de Ángel, Barranco Hondo, Los Toros).

ABSTRACT This article deals with the subject of the Paleolithic study in 2000, with new contributions for the Lower Paleolithic in Teruel (elephants of Cuesta de la Bajada) and Rioja (Najerilla series). In Middle Paleolithic the value of the Mousterian facies is studied in order to know the sites functionality, analyzing the cave of Gabasa like "butchery model" (shared with carnivores) and Peña Miel Cave like permanent habitat (with the bones amortised). Also, we consider the validity of the term Ebro Frontier in 40,000 since there are Late Mousterian to the North of this river. We also study the deposits of the Early Upper Paleolithic at the Ebro Valley (Peña Miel in Rioja, Angel in Teruel; Zatoya, Mugarduia and Alquerdi in Navarre). In the Magdalenian the microspace organization of the level"e" of Abauntz Cave is analyzed with the last data of the second room and is studied the extension of this culture by the Ebro Valley from the PrePyrenean area (Chaves, Forcas, Peña 14, Parco, Montlleó) to territories not known some 
years ago and that mark to the extension toward the Meseta through the Henar valley(Peña del Diablo, Vergara and Alexandre shelters) and Moncayo Mountain (Bolichera cave). The route towards the SE would be marked by the sites of the Guadalope and Mijares rivers (Angel, Barranco Hondo, Los Toros shelters).

Palabras claves Paleolítico, Valle del Ebro

Key words Paleolithic, Ebro Valley

Si hoy que están tan de moda los sondeos de opinión nos preguntaran a los prehistoriadores españoles quién es nuestro compañero más entrañable dudo que hubiera nadie que superara a Enrique Vallespí, un hombre querido por todos sus colegas, por todos sus alumnos. Como investigador fue atípico en su tiempo por su afición a los pobres talleres de sílex cuando todos buscaban espectaculares poblados urbanos, siendo además pionero en actividades de prospección, de las auténticas de zapatilla y bocadillo y charleta en el bar del pueblo con el boticario, el cura o el alguacil. Me siento honrada en participar en el homenaje que la Universidad de Sevilla le dedica con este número monográfico sobre Paleolítico.

Y siento tener que escribir de nuevo un estado de la cuestión de la investigación de esta etapa en el Valle del Ebro ${ }^{1}$ por dos razones: la primera porque acabo de hacerlo por encargo en otras publicaciones, como la Crónica de Caesaraugusta 1993-1998 o la ponencia del XXVI CNA a celebrar en Zaragoza, y no me gusta republicar, volver a "más de lo mismo"; la segunda porque Enrique es tan "filósofo", tan ácrata aunque su aspecto clásico nos engañe, que me hubiera gustado dedicarle un artículo diferente, como es "La captura del ciervo vivo en el arte levantino". Tiempo habrá para hacerlo; ahora me ceñiré al tema propuesto por los editores aunque, en su honor, intentaré darle un enfoque menos académico.

\section{EL PALEOLÍTICO DEL VALLE DEL EBRO EN LA HISTORIOGRAFÍA}

\section{El primer tercio del siglo XX: de curas, marqueses y otros desocupados}

En esta etapa pionera se asiste a un hecho generalizado a toda España: la investigación prehistórica es llevada a cabo fundamentalmente por sacerdotes, algo aburridos en sus parroquias rurales, como Mosen Vicente Bardaviu en Alcañiz, Albalate, Villanueva de Sigena o Sena o muy activos y "globalizados" como el Abate Breuil, omnipresente en todos los yacimientos de España y Francia. Nuestros nobles, como el Marqués de Cerralbo, prefirieron épocas más atractivas que el Paleolítico, quedando únicamente el testimonio de la actuación del Marqués de Loriana en Berroberría que fue funesta para el yacimiento. Tuvimos otros semidesocupados que les suplieron: un pintor como Cabré o eruditos locales entre los que se encontraban notarios o boticarios (Grupo del Bajo Aragón)

La Rioja, y en ella la cueva de Peña Miel, en Nieva de Cameros, tiene el honor de ser la primera cueva paleolítica que se excavó en la Península Ibérica, algunos años antes de que Sautuola comenzara sus trabajos

1. Incluimos las Comunidades Autónomas de Aragón, Navarra y Rioja, aunque algunas zonas de Teruel pertenezcan a la Cuenca del Turia o del Júcar (valles del Mijares y Alfambra principalmente) y otras de Navarra viertan sus aguas al Atlántico en la vertiente francesa (Berroberría y Alquerdi). Se incluye también la parte de la provincia de Soria que vierte al Jalón (yacimientos del valle del Henar, por ejemplo) y toda la provincia de Lérida inscrita en la Cuenca del Segre. 
en Altamira. Fue un despistado Eduard Lartet acompañado de su hijo Luis, quien acudió en 1863 a la Sierra de Cameros, buscando yacimientos similares a los que acababa de excavar en Francia y que dieron nombre a las culturas paleolíticas: Le Moustier, Aurignac, La Madeleine. Una enfermedad gastrointestinal obligó a Lartet a quedar en cama y la inexperiencia de Luis le llevó a desechar todas las piezas de cuarcita que constituyen el $90 \%$ de la industria, pero salvó el material de la ocupación auriñaciense (en sílex y a techo de la secuencia) que publicó en 1866 en la Revue Archéologique. A esta visita siguió a principios de siglo la de paleontólogos en busca de rinoceronte, como Ismael de Pan, que publicó sus pesquisas en 1921, aunque pasarán más de 100 años desde su descubrimiento hasta que la cueva sea de nuevo excavada en los años ochenta. En Navarra Hugo Obermaier cita en su Hombre Fósil de 1925 el hallazgo de cuarcitas talladas en Zúñiga y José Miguel de Barandiarán comienza a excavar la cueva de Abauntz sin llegar a los niveles paleolíticos.

En Aragón los estudios sobre el Paleolítico pasan por una fase "optimista" en la que toda piedra que aparecía era clasificada como magdaleniense o solutrense sin ningún criterio (es la época de los hallazgos en los despoblados de Albalate y Alcañiz o de los Montes de Torrero de Zaragoza; o del ingenuo pez grabado sobre el córtex de una lasca de Sena). En otros casos, en los estudios relacionados con el arte rupestre levantino, las industrias al pie de las pinturas se declaran interesadamente paleolíticas para defender la cronología antigua de este arte, como es el ejemplo de Calapatá "premagdaleniense" o de Secans, solutrense (Cabré y Pérez Temprado 1921) Baste decir que de todos los yacimientos que Vicente Bardaviu clasificó como paleolíticos en su Discurso de Ingreso en la Real Academia de Ciencias Exactas, Físico-Químicas y Naturales de Zaragoza en 1923, ninguno de ellos lo era.

\section{La etapa escéptica y racional de los años 50 a 70}

En una segunda etapa, de los años cincuenta y sesenta, tras el paréntesis de la Guerra Civil y la primera postguerra, asistimos en Aragón al fenómeno contrario: una desmitificación del Paleolítico, ya que se hace una revisión tan crítica de los datos por parte de Ripoll en la Prehistoria del Bajo Aragón (1956) y de Vallespí (1961) que se niega el carácter paleolítico de la mayoría de los yacimientos. Solo los Pedreñales de Castelserás parecían salvarse de la quema.

En líneas generales la Universidad y los Museos dinamizan las excavaciones arqueológicas que pasan ahora a profesionales de la arqueología. La presencia desde 1949 de Antonio Beltrán en la cátedra de Arqueología de la Universidad de Zaragoza supuso una intensificación de la actividad arqueológica, plasmada en la actividad de sus colaboradores, como Manuel Pellicer o Enrique Vallespí, quien se especializó en talleres de sílex que interesaban poco a sus colegas. Ellos llenan con sus trabajos las décadas de los años cincuenta y sesenta. A Vallespí se debe una intensa labor prospectora e interesantes revisiones de las industrias líticas de los términos de Fabara (La Noguera), Mazaleón (Secans), Cretas (Gascons), Valderrobres (Sta. Magdalena) o numerosos talleres de sílex en término de Torre los Negros (Vallespí 1959).

Si la década de los sesenta fue de Pellicer y Vallespí, que partieron para otros destinos universitarios, la de los setenta será de Ignacio Barandiarán, quien desde 1968 se dedicará a realizar una serie de excavaciones sistemáticas que pueden considerarse básicas para el conocimiento de la Prehistoria Aragonesa. Además se ampliará por vez primera la investigación al territorio del distrito universitario de Zaragoza: el Valle Medio del Ebro. Las cuevas de la Eudoviges de Alacón o Los Casares de Riba de Saelices serán la primera aportación clara de la existencia de Paleolítico en esta zona. El yacimiento de Eudoviges, el primero "auténtico" de Aragón, será además analizado con los nuevos criterios de la escuela de Burdeos, apoyados en la tipología empírica y en una estadística elemental de gráficas acumulativas, algo simplista pero válida para su época. 
En Navarra, la investigación del Paleolítico gira en esta época en torno a los hallazgos de la cantera de Coscobilo, en Olazagutía, desde que Ruiz de Gaona descubriera las primeras piezas a comienzo de los cuarenta. Los estudios tipológicos, inclinándose unas veces por una cronología musteriense otras por una solutrense, corrieron a cargo de Maluquer de Motes (1954), Vallespí solo (1975) o en colaboración con Ruiz de Gaona (1970 y 1971) o Beguiristain (1974). Es también la época en la que Maluquer de Motes comienza a excavar la cueva de Berroberría, ya expoliada años antes por el Marqués de Loriana. Entre los hallazgos sueltos se publica el bifaz de Lumbier en 1958 por parte de Marcos Pous y Mensua y años más tarde Vallespí y García Serrano publican un cordiforme alargado de Estella. En la Rioja sólo el hallazgo del bifaz de La Torrecilla en Calahorra, dado a conocer en 1973 por Barandiarán, aportó alguna novedad paleolítica, publicando Vallespí dos años después la primera síntesis sobre Achelense y Musteriense en el alto Valle del Ebro, donde puede verse toda la bibliografía sobre el tema (Vallespí 1975) .

\section{De los ochenta al 2000: jugamos con los ordenadores}

El traslado de Barandiarán a la Universidad de La Laguna en 1976 por cuestiones académicas fue un duro golpe para la Prehistoria del Valle del Ebro, aunque sus numerosos discípulos continuaron la labor por él emprendida. La concesión al equipo de la Universidad de Zaragoza de cuatro proyectos Cicyt sucesivos sobre el Paleolítico en el Valle del Ebro y el paso del Tardiglaciar al Holoceno (PB 87/624; 90/588; 93/307 y 97/1030) ha dinamizado las prospecciones y excavaciones paleolíticas en la zona con un soporte financiero que ha permitido pagar viajes, dibujos o informatización de datos. Las Comunidades Autónomas de Aragón, Rioja y Navarra han subvencionado con algún altibajo las excavaciones, si bien hay que lamentar que estas últimas se ocupen ahora únicamente de las actuaciones de urgencia, echando por tierra en el caso de Navarra una espléndida tradición investigadora que arrancaba de la época de Blas Taracena y Maluquer de Motes.

En Aragón se excavarán los yacimientos musterienses de Gabasa (Utrilla y Montes), Fuente del Trucho y Castelló de Plá (A. Mir), Castelserás, Rueda de Jalón y Pozuelo de Aragón(Utrilla y Tilo), Toros de Cantavieja (Utrilla y Álvarez) o los pertenecientes al Paleolítico Superior de Chaves (P. Utrilla), Forcas I de Graus (Utrilla y Mazo), Peña del Diablo de Cetina (P. Utrilla), abrigos Vergara y Alexandre de Deza (Utrilla y Blasco), Roca Hernando (Utrilla, Villaverde y Martínez) o abrigo de Ángel (Utrilla y Domingo). El Pleistoceno Medio verá por fin un yacimiento auténtico: La Cuesta de la Bajada en Teruel estudiada por Santonja y quizá Las Callejuelas en Monteagudo del Castillo (Tilo y Utrilla), junto a los consabidos hallazgos sueltos de bifaces, la mayoría en la provincia de Zaragoza: Caspe, Fuentes de Jiloca, Mara, Calatayud, Borja... (Utrilla, Mazo, Aguilera y Blasco), aunque también se han documentado en La Litera (Mir y Rovira).

Las investigaciones de esta etapa tienen un hito importante en Navarra con la aparición de la síntesis Prehistoria de Navarra (Barandiarán y Vallespí 1984) donde se documentan los talleres del Paleolítico Inferior y Medio de la Sierra de Urbasa en las áreas de El Raso y Otxaportillo; o ya en el Paleolítico Superior las excavaciones de Barandiarán y Cava en Berroberría, con una importante secuencia magdaleniense; de Utrilla y Mazo en Abauntz, con una estratigrafía que arranca en el Musteriense, continúa en el Solutrense y Magdaleniense y termina con las ocupaciones neolíticas y los enterramientos calcolíticos. A techo de la secuencia los romanos del Bajo Imperio escondieron sus pobre tesorillos ante la amenaza de las invasiones bárbaras. En la zona de Echauri J. Nuin (1996) ha realizado hallazgos magdalenienses y solutrenses en abrigo y al aire libre mientras que Javier Armendariz (1998) ha publicado el hallazgo reciente de dos nuevos bifaces en el Ega.

En la Rioja la actividad prospectora de algunos sacerdotes como Hilario Pascual en Calahorra y sobre todo Pedro Rioja en el Najerilla ha dado como resultado el hallazgo de interesantes series líticas con abundancia de bifaces y hendedores que han sido publicados por Utrilla y Rioja en colaboración con Rodanés para Cañas (1986), de Mazo para Villar de Torre (1986) y de Montes para Badarán (1987) publicación donde 
puede verse la síntesis de toda la zona del Najerilla. La excavación de la cueva de Peña Miel en 1980, 1981 y 1984 por parte de P. Utrilla tendrá su memoria en 1987, redactada en colaboración con L. Montes y otros autores, si bien su interpretación funcional, planteada en el Homenaje a González Echegaray (Utrilla 1994), no se ha publicado hasta tener el estudio tafonómico realizado por F. Blasco, siendo presentada en el Coloquio de Capellades (Blasco, Montes y Utrilla 1996) ${ }^{2}$.

Tres magníficas Tesis Doctorales tratarán en esta época sobre temas paleolíticos: una clásica, de Lourdes Montes, sobre la visión global del Musteriense del Valle del Ebro y dos "rompedoras": la de Carlos Mazo sobre el análisis funcional de los artefactos líticos del nivel magdaleniense de Abauntz y la de Fernanda Blasco sobre la Arqueozoología de las cuevas de Peña Miel y Gabasa. El primero, sagaz y extremadamente crítico, demostró por ejemplo que los buriles de Abauntz no sirvieron para su teórica función (grabar o ranurar) sino que fueron utilizados como raspadores (los de truncadura, asociados a ellos en el mismo espacio) o como perforadores (algunos diedros hallados en la misma zona que estos últimos). Tampoco los ocres sirvieron para pintar sino para proteger las pieles de la putrefacción, por lo que la supuesta "área artística" quedaba reducida al trabajo de las pieles. F. Blasco, persona intuitiva y brillante pero también metódica en su trabajo, confirmó con el análisis tafonómico la hipótesis de partida que le planteamos: que las facies musterienses basadas en criterios exclusivamente líticos no sirven para delimitar la funcionalidad de los yacimientos como sugirió Binford. Una vez más se demostraba que las facies habían quedado obsoletas.

En cuanto al trabajo de campo poco variarán las técnicas de excavación que seguirán el magisterio de Barandiarán, aunque ahora se valorará en lo posible la excavación horizontal para intentar reconstruir las áreas de actividad de la ocupación, estableciendo estudios de isodensidades, análisis tafonómico y traceológico, con participación de diferentes especialistas . Sin embargo habrá arqueólogos que, influenciados por Pincevent, llegarán a rizar el rizo metodológico, olvidando que no están en las arenas del Sena sino en un pedregal con alteraciones postdeposicionales y tomando datos de coordenadas en yacimientos residuales que jamás utilizarán porque son inútiles en su caso. No son conscientes de que están trabajando con dinero público que espera resultados en un tiempo razonable y la presentación de memorias de excavación que no sean ni meros inventarios ni fantasiosos castillos en el aire. Otros, en su interés de demostrar que dominan los sistemas informáticos, aplican análisis microespaciales a niveles alterados o con cientos de años comprimidos en pocos $\mathrm{cm}$. Solo las ocupaciones efímeras o estacionales en un estado privilegiado de conservación pueden dar juego para estos análisis. En el caso de Gabasa, por ejemplo, sólo uno de sus ocho niveles, el "g", podía dar resultados medianamente coherentes.

Los nuevos programas informáticos recubrirán de una pátina pseudocientífica las publicaciones actuales, pecando a veces de utilizar la estadística con demasiada ligereza (análisis factorial, de componentes principales, K-means, dendrogramas, lien...) . Pero eran tan sugestivas las aplicaciones como Statview, Kaleida o Systat y eran tan monótonas la tipología y la estratigrafía que no nos resistimos a ir más allá, en un imposible intento de captar alguna sombra del hombre prehistórico. Nos tememos que la estadística es capaz de demostrar cualquier hipótesis que nos propongamos. Sólo hay que buscar la rotación adecuada.

2. Sería conveniente que cuando se hagan comentarios sobre lo "clásico" de la monografía tipologicista de Peña Miel (señalando la falta de integración de los resultados de los diferentes autores en una síntesis socio-económica) (Estévez y Vila 1999) se tenga en cuenta la interpretación funcional que completa la memoria y que fue planteada en los dos artículos citados: el de 1994 en el Homenaje a G. Echegaray (que recibió las felicitaciones de muchos paleolitistas españoles y americanos, a pesar de que no les haya gustado a estos dos autores) y de 1996, artículo ya publicado cuando apareció en 1999 este último libro que cita publicaciones de 1998. Sorprende este olvido del Coloquio de Capellades, editado además en Cataluña, en unos autores que han sido capaces de leer (y les admiro sinceramente por ello, en una época en la que a los docentes atribulados nos falta tiempo) toda la bibliografía paleolítica del último siglo. Quizá era demasiada para poder tener una digestión reposada. Por otra parte recordamos una vez más que Lartet vació la parte central de la cueva, los dos tercios de la ocupación, por lo que no había lugar a realizar estudios microespaciales sobre los restos residuales adosados a las paredes. Es perder el tiempo. 


\section{LAS APORTACIONES MÁS SIGNIFICATIVAS DE LOS ÚLTIMOS AÑOS: ALGUNOS TITULARES DE PRENSA PARA LA "REVISTA DEL PALEOLÍTICO"}

En la introducción he explicado que deseaba eludir una enumeración de datos y cifras que ya he publicado en otros lugares (Utrilla 1995 y 1997a y b) por lo que, animada por el artículo sobre "El lobo feroz" que publicó Barandiarán (1993) en Veleia, donde con su agudo sentido crítico recoge el Corpus de encabezamientos de choque o de "marketing" en la bibliografía prehistórica ${ }^{3}$, me atrevo a buscar aquellos titulares de prensa que hubieran sido posibles en una hipotética Revista del Paleolítico del Valle del Ebro, aunque no puedo despojarme de un desarrollo más académico de la noticia. De más antiguo a más reciente los titulares de actualidad serían estos:

\section{Teruel existe : aparecen elefantes en nuevos yacimientos al aire libre}

Tras casi cien años de soledad como única cita bibliográfica del Paleolítico Inferior, las Terrazas de San Blas de Teruel se han visto acompañadas por un nuevo yacimiento turolense: La Cuesta de la Bajada a la que Manuel Santonja ha dedicado tres campañas de excavación arqueológica. Se trata de una cantera próxima a la ciudad cuyo yacimiento conserva una extensión de $1000 \mathrm{~m}^{2}$ e integra una serie de niveles de origen fluvial y lacustre datada en la segunda parte del Pleistoceno Medio por una fecha mínima de 137,9=-10.07 Ka, obtenida por termoluminiscencia. La macrofauna, compuesta por Elephas antiquus, Dicerorhinus hemitoechus, Cervus y Equus chosaricus, corrobora esta cronología, ambientando la ocupación en un momento templado, como debió ser usual durante la mayor parte del Pleistoceno Medio en la Península Ibérica. El Elephas antiquus y el Eliomys quercinus documentan un paisaje de bosque, mientras que las demás especies son propias de un medio abierto, con abundantes herbáceas.

El utillaje lítico está compuesto por utensilios de pequeño tamaño elaborados sobre fragmentos de lasca y de núcleo, estando ausentes los utillajes de tipo bifacial. Destacan los denticulados y las raederas ordinarias dobles, con presencia de algunos becs. Como materia prima utilizan preferentemente chert y caliza, mientras que el sílex no sobrepasa el 5\% en ningún nivel. Este dato explica la ausencia de útiles macrolíticos, dada la escasez de materias primas aprovechables.

La clasificación cultural del yacimiento es siempre problemática ya que se encuentra en ese momento de tránsito del Paleolítico Inferior al Medio que suele clasificarse como Achelense Superior si hay bifaces y como Musteriense si sólo existe material sobre lasca. Sin embargo la tecnología utilizada (sobre núcleos levallois recurrentes, discoidales no levallois y poliédricos) se aleja poco de otras series del final del Pleistoceno Medio como Solana de Zamborino, en Granada, o Bolomor, en Valencia. La disponibilidad de materia prima de tamaño suficiente parece ser el factor clave para que aparezcan o no bifaces y hendedores (Santonja et alii 2000).

El cazadero de Monteagudo del Castillo, en la cuenca del Mijares, es un buen ejemplo de kill-site o butchery-site de grandes herbívoros (caballos y bóvidos). Situado en un lugar estratégico, fue excavado con permiso oficial por el Padre Adrover, quien obtuvo una gran cantidad de restos que quedaron desperdigados en el Instituto de Paleontología de Sabadell, en departamentos universitarios madrileños y en el Museo de Ciencias Naturales de París, donde Vere Eisenmann (1989-90) realizó la única publicación acerca de las series de caballos del yacimiento.

3. Por ejemplo en la bibliografía anglosajona Binford "Willow smoke and dog's tail"; Bahn "No sex, please, we're Aurignacians" o Freeman "Kaleidoskope or tarnished mirror?" o en la española Bernabeu, Aura y Badal "Al Oeste del Edén"; Ruiz-Gálvez "La novia vendida" o "Canciones del muchacho viajero" o el ya clásico de Nocete "Estómagos bípedos/Estómagos políticos" 
Ángeles Tilo (1994) fue la primera en realizar catas arqueológicas en 1991, continuando en 1999 Pilar Utrilla en una segunda campaña. El perfil refleja una estratigrafía en la que se suceden costras muy cementadas, en cuya base aparecen capas de bloques agudos que suelen contener restos de fauna muy brechificados, intercalados de series de arcillas oscuras y gravillas amarillas más o menos cementadas, todas ellas fértiles.

Con un material lítico a base de raspadores carenados y de hocico, perforadores y denticulados de pequeño tamaño, Tilo duda de la cronología musteriense asignada al yacimiento por las mandíbulas de los caballos, proponiendo una posible cronología Paleolítico Superior Inicial.

Eisenmann por su parte dudaba en atribuir una fecha concreta a unas series de mandíbulas de caballos cuyo tamaño era intermedio entre las musterienses de Combe Grenal y las magdalenienses del País Vasco, terminando por proponer una cronología en torno 70.000 años, basándose en que "los caracteres sedimentológicos de la brecha fosilífera son poco compatibles con una edad tan reciente".

Sin embargo no debería descartarse una edad intermedia, como es el Paleolítico Superior Inicial que propuso Tilo, ya que las piezas más claras son los raspadores carenados y de hocico que encajarían perfectamente en un Paleolítico Superior Inicial, al cual, con muchas dudas, podrían corresponder también los grabados profundos de la vecina Roca Hernando (Cabra de Mora) (Utrilla, Villaverde y Martínez 2001). Añádase además que el tipo de fauna (caballos y bóvidos) concuerda con los animales elegidos como presas por las gentes del Auriñaciense de la Península Ibérica (aunque también por los musterienses) pudiendo interpretarse como un lugar de matanzas y descuartizado de caballos, a juzgar por la abundancia de sus restos.

En contra de esta opción cronológica estaría el hecho de que no se ha encontrado colágeno para datar los huesos por AMS ni en Oxford ni en Groningen, quizá por su excesiva antigüedad (aunque también han podido ser alterados por la costra calcárea) y que los pequeños raspadores carenados y los becs denticulados son habituales en series de fines del Pleistoceno Medio, como las de Bolomor, datadas por termoluminiscencia entre 150 y $120 \mathrm{Ka}$ (Fernández Peris et alii 2000).

En la Rioja no hemos encontrado fauna pero sí series líticas en el río Najerilla, distantes tan sólo $60 \mathrm{Km}$ de Atapuerca. Algunas se localizan sobre el glacis 4 del río (Charcón, Cirueña, Suertes Viejas y Suertes Nuevas), otras, como Cerro Villar, aparecen como enlaces de los glacis 3 y 4 mientras que La Ra y Entrematas se sitúan sobre el glacis 3 y Pedernales, Arenas y Arenilla lo hacen sobre el glacis 2 . Todas ellas han sido objeto de publicaciones a las que nos remitimos para un mayor estudio de detalle (Utrilla, Rioja y Mazo 1986; Utrilla, Rioja y Rodanés 1986; Utrilla, Rioja y Montes 1987).

De los doscientos bifaces recuperados, existe una mayor representación en Cerro Villar y en los yacimientos situados sobre el glacis 4, mientras que entre los hendedores destacan dos focos, Suertes Viejas y Arenas, en los que constituyen la mitad de la industria bifacial, siendo además los ejemplares más singulares de todo el conjunto (tipos III, V y VI).

Según los estudios geomorfológicos de los glacis de Ibáñez, Peña y Pellicer y el contenido lítico de las series, podríamos distinguir, a priori, las siguientes épocas y conjuntos:

- en un primer momento, que podemos situar en teoría en un Achelense Medio o Superior, se ocuparían los yacimientos del glacis 4. En ellos se realizarían distintas funciones: así Suertes Viejas desarrollará una actividad supuestamente relacionada con el trabajo de la madera ${ }^{4}$ o con el descuartizado de

4. Un estudio traceológico sobre 11 hendedores del Najerilla realizado por C. Mazo demostró que de los 4 fabricados en cuarcita que conservaban huellas de uso, 3 habían servido para el trabajo cierto de la madera quedando la duda de si el cuarto había trabajado madera o hueso. El único de sílex que presentaba huellas (sólo en la mitad izquierda del filo debido a la empuñadura) había sido utilizado para procesar carne. La asociación cuarcita/trabajo de la madera parece deberse a las propiedades mecánicas de esta materia, apta para procesos laborales que implican fuertes tensiones, similares al uso actual de hachas y azuelas. Esta es seleccionada por el hombre para fabricar sus hendedores, incluso en aquellos lugares como el Najerilla en los que abunda el sílex como materia prima. La ventaja respecto al sílex en estas operaciones es que estos hendedores mantenían el filo intacto más tiempo debido a una tendencia al esquirlamiento mucho menor (Utrilla y Mazo 1996a). 
animales, dada la abundancia de hendedores; Charcón y Suertes Nuevas, situados junto a charcas o lagunas, podrían tener relación con la caza; Cerro Villar aprovisionaría de sílex a todo el conjunto, efectuándose allí el primer proceso de talla, y Cirueña, con su alto porcentaje de núcleos podría ser utilizado en un segundo momento de talla, quizá en el lugar de hábitat dada su posición elevada y a resguardo del viento.

Las características comunes a estos yacimientos vienen marcadas por un dominio de la pátina amarilla en las zonas bajas (Cañas) y de la blanca en las altas (Cerro Villar y parte alta de Cirueña); una escasa tecnología levallois (más alta en Cerro Villar donde abunda la materia prima); una baja presencia de útiles del Paleolítico Superior, salvo en el caso de Charcón, que pudo ser reocupado, y sobre todo, un alto porcentaje de bifaces gruesos en el conjunto de piezas retocadas.

— en un segundo momento, se ocuparían los yacimientos del glacis 3, situados al pie de Cerro Villar. Nos referimos a Entrematas de Badarán y La Ra de Villar de Torre. Cerro Villar siguió aprovisionando de sílex a estos yacimientos, a pesar de que Entrematas posee también nódulos en superficie y pudo realizar la misma función.

Las características que los definen se concretan en una fuerte presencia levallois, manifestada en el Ilty de Entrematas y en el dominio de núcleos levallois en La Ra; en un dominio de la pátina blanca en el sílex; y desde el punto de vista tipológico, en un avance del Grupo Paleolítico Superior, junto a un descenso apreciable de piezas bifaciales. Entre estas aparecen además algunos útiles considerados como "progresivos" como un bifaz subtriangular y un hendedor de tipo V, lo que, de aceptar la tipología de fósiles directores, llevaría la ocupación al Achelense Final o al Musteriense de Tradición Achelense. La funcionalidad de estos asentamientos estaría marcada por el alto porcentaje de núcleos en Entrematas y La Ra donde se efectuaría la talla del sílex, probablemente secundaria.

- en un tercer momento, de cultura musteriense, se ocuparían Arenas y Arenilla, los yacimientos del glacis 2, los cuales se diferencian de los demás por la fuerte presencia de raederas Quina. Un buen componente de piezas del Paleolítico Superior (raspadores carenados, buril arqueado, láminas "auriñacienses" algo espesas) nos llevan a rastrear una posible presencia auriñaciense, documentada también en la riojana cueva de Peña Miel.

\section{Gabasa y Peña Miel. Dos modelos de ocupación en el Musteriense: cazadero vs. hábitat permanente}

Se trata de dos yacimientos recientemente excavados (Utrilla et alii 1987; Montes 1988; Utrilla y Montes 1993) con niveles datados en fechas similares (Montes, Utrilla y Hedges 2001) y con una industria lítica clasificable en la misma facies, en el límite entre el Quina y el "Musteriense típico, rico en raederas". En principio, y según la clásica interpretación de Binford, ambos yacimientos deberían tener la misma funcionalidad puesto que presentan idénticos índices líticos, pero un estudio detallado de otros parámetros como son el aprovechamiento de la fauna o las estructuras de hábitat nos demuestra que cada asentamiento fue utilizado para usos diferentes.

Así Gabasa sería un claro ejemplo de cazadero, un lugar compartido alternativamente por el hombre con hienas y otros carnívoros, como luego veremos, mientras que Peña Miel sería un lugar de habitación permanente, con claros testimonios de hogares (Utrilla 1994). Busquemos un titular de prensa, de "marketing", para cada uno de ellos. 
Hambre en Peña Miel: comieron el tuétano de los huesos e hicieron caldo con hueso de caña y espinazo

Peña Miel (Nieva de Cameros, La Rioja) es una cueva de dimensiones medias-pequeñas, con una buena orientación Sureste, perfecto camuflaje de su boca, empedrado natural del suelo y ubicación privilegiada sobre el río Iregua, que controla un territorio de explotación muy distorsionado por los grandes farallones que cierran el valle.

Presenta en su nivel $g$ hogares bien formados, una elección no selectiva de la materia prima (uso preferente de la cuarcita por ser la más abundante en el lugar) y un agotamiento de los escasos núcleos de sílex. La existencia de núcleos y abundantes desechos de talla indican que se trabajó la piedra en el mismo yacimiento, siendo 400 las piezas retocadas. Tipológicamente se adscribe a la facies Quina, dada la abundancia de raederas de una tecnología no levallois y la presencia de los especiales tipos carenados (limazas, raederas transversales).

La fauna de Peña Miel es escasa en número de restos, dado el grado de aprovechamiento de los huesos y su reducción a esquirlas. Las especies identificadas por Altuna reflejan un paisaje de bosque (ciervo, sarrio y corzo ), combinado con el hábitat de roquedo (cabra y sarrio) y praderas más abiertas (caballo y rinoceronte). No están documentados los carnívoros, salvo un canino inferior de zorro. Los metapodios de ciervo son muy abundantes (111 ejemplares), lo que contrasta con la escasez de falanges del mismo animal (3). En opinión de Altuna (1987) éstas quedarían en la piel al desollar al animal, mientras que los metapodios serían aportados a la cueva al traer la pata completa del ciervo. Habrá que suponer que el troceado de la caza se realizaría en otro lugar, lo que explicaría también el abandono de la cabeza ya que apenas se encuentran restos del esqueleto craneal.

La industria ósea semielaborada es muy abundante, presentándose los huesos escindidos longitudinalmente, retocados y con frecuentes marcas de sílex producto del procesado de los mismos. Ignacio Barandiarán (1987) computa 8986 evidencias óseas en cinco metros cuadrados excavados, con un peso total de $39 \mathrm{Kg}$. La razón de esta transformación secundaria de los huesos parece estar en un mejor aprovechamiento del animal (extracción de la médula ósea, utilización de tendones). Fernanda Blasco(1992: 235-242.) ha publicado distintos ejemplos de estrías producidas por un instrumento lítico en contacto con el hueso. Allí se identifican huellas de corte, de desarticulación, de extracción de la piel, de separación del húmero del cúbito-radio, de extracción del músculo, de descarnación etc. Es posible además observar el proceso de fracturación del hueso al extraer la lasca, con huellas de bulbo y ondas de percusión, similares a las que aparecen en la industria lítica.

La actividad humana en la fracturación y escisión longitudinal de las diáfisis se observa en una gran cantidad de piezas óseas (alrededor del $38 \%$ poseen evidencias de percusión activa), siendo apabullantes las cifras de esquirlamiento óseo: 7660 esquirlas por $\mathrm{m}^{3}$, pertenecientes sobre todo a diáfisis, no encontrándose en cambio las epífisis correspondientes a los mismos huesos.

Esta actividad tendría como fin un mejor aprovechamiento del animal que debió ser muy escaso en la dieta alimenticia: la extracción de la médula ósea como aporte substancial de proteínas. La ausencia de vértebras y de la parte esponjosa de las epífisis podría indicar su eliminación en la elaboración de un caldo para aprovechar la grasa (Blasco, Montes y Utrilla 1996), tal como han propuesto Delpech y Rigaud (1974) para la cueva francesa de Flageolet, basados en los estudios etnológicos de Binford (1988) sobre los esquimales nunamiut.

\section{Compartamos la cueva de Gabasa: tú en invierno, yo en verano}

Un estudio comparativo de las actividades realizadas en Gabasa y Peña Miel (ambas contemporáneas y pertenecientes a la misma facies cultural) fue propuesto como modelo de interpretación funcional en nuestro artículo "campamentos base, cazaderos y santuarios" que dedicamos a González Echegaray (Utrilla 1994). 
Fernanda Blasco (1995 y 1997) desarrolló en su libro los pormenores del estudio arqueozoológico, mientras que en el artículo del Congreso de Capellades expusimos la síntesis de la interpretación de los dos yacimientos, basados en todos los parámetros posibles como son la presencia de hogares, la industria lítica, la organización espacial y la tafonomía (Blasco, Montes y Utrilla 1996).

Las características que nos permiten la clasificación de Gabasa como cazadero son las siguientes:

— posee gran abundancia de restos de ungulados comestibles: 5978 huesos reconocibles de herbívoros que pertenecen como mínimo a 451 individuos (cabra, ciervo, caballo, bóvido, sarrio, corzo).

- también cuenta con diez especies de carnívoros, entre ellos la hiena y los cánidos de mediano tamaño como el lobo y el Cuon, animales que podrían ser responsables potenciales de la matanza de algunos herbívoros y que pueden arrastrar hasta las cuevas parte de sus presas. En total 80 individuos (21 lobos, 13 hienas, 12 linces, 10 zorros, 8 osos de las cavernas, 8 gatos monteses, 5 panteras de diferentes especies y 3 Cuon alpinus).

- en cuanto al tipo de huesos que se encuentran en el yacimiento es significativa la abundancia de cabezas (dientes, cuernos) y extremos distales de las patas (metapodios, tibias, cúbitos, radios), siendo escasos los fémures, húmeros y escápulas. Ello podría interpretarse como una selección por parte del hombre de las mejores partes comestibles, abandonando cabezas y extremos de las patas en el cazadero y llevándose los jamones, lomos, solomillos... al campamento permanente de hábitat, situado en otro lugar.

- carece de estructuras de acondicionamiento e incluso de hogares (excepto en nivel h), siendo escasos los carbones.

- la industria lítica, a base de puntas, limazas y raederas (facies Quina o Típico), habla de una actividad relacionada con la caza y el procesado de la carne. Los restos de talla, en cambio, son escasos en Gabasa, presentando las lascas frecuentes huellas de uso.

— ausencia de restos óseos trabajados a modo de compresores, retocadores o tensores. Sí existen huellas de corte con sílex sobre los huesos.

- son frecuentes las huellas de dientes de carnívoros sobre los huesos de animales. Así es posible observar huellas circulares de caninos de cánidos sobre falanges y cabezas femorales (Blasco 1992: 245), así como las estrías producidas por el arrastre de los dientes de los carnívoros sobre la superficie del hueso, las punciones sobre el tejido óseo machacado, actividades de mordisqueo en cabezas de huesos largos etc. En resumen, tanto carnívoros como hombres llevaron a cabo sus actividades de caza en Gabasa.

El problema del arqueólogo se plantea en cómo discernir a quién se debe la matanza de los herbívoros de Gabasa, si al hombre que dejó sus puntas y raederas en el yacimiento o a los carnívoros que lo habitaron alternativamente, ya que la evidencia de la actividad humana se enmascara con la del resto de los moradores o visitantes de la cueva. Esa cuestión ha sido resuelta con un brillante estudio tafonómico realizado por Fernanda Blasco (1995 y 1997) y por el estudio microespacial de la distribución de los restos óseos en el nivel menos alterado por procesos postdeposicionales (Blasco, Montes y Utrilla 1996) el cual determinó curvas de isodensidad de restos con atributos concretos.

El primer atributo considerado fue el taxón al que pertenece el resto óseo. Los más abundantes son la cabra, el caballo y el ciervo. Estos dos últimos, concentraban sus restos en la misma zona, mientras que en la parte opuesta se distribuían los restos de cabra. El segundo atributo quedó referido a los restos que poseían marcas de la actividad directa del hombre (marcas de cortes con sílex o fracturas ) o de los carnívoros (huellas circulares dejadas por los caninos de los cánidos).

Analizados en conjunto estos dos atributos, resultaba evidente que los restos óseos que portaban pruebas directas de la actividad humana se concentraban en el área que presentaba mayor número de restos de ciervo y équidos, principales especies afectadas por el hombre en el aprovechamiento de sus recursos. En este 
área, además, la actividad de los carnívoros permanecía prácticamente ausente. Al mismo tiempo, la actividad antrópica decaía hacia los cuadros donde se encontraban las mayores densidades de huesos de cabra.

Un nuevo factor de análisis vino determinado por la edad a la que fueron cazados los herbívoros: alrededor del $60 \%$ de los individuos de ciervo y caballo habían muerto durante el primer verano de su vida, luego habían sido abatidos por el hombre (quien dejó en ellos sus huellas de corte) en el periodo templado de las estaciones, en verano-otoño. En cambio, la cabra (asociada espacialmente a los carnívoros) presentaba un perfil de mortalidad con escasez de infantiles y dominio absoluto de individuos adultos. Por tanto, este animal fue cazado por los carnívoros en invierno, en los periodos no propicios para la cría. Los cánidos que han dejado sus huellas circulares en los huesos de cabra y quizá las hienas (de las que no queda resto pues sus poderosas mandíbulas trituran los huesos) habrían arrastrado a las cabras hasta la cueva de Gabasa, su cubil de invierno, quizá para alimentar a sus propias crías. Existiría así una alternancia de ocupaciones por parte del hombre (verano) y los carnívoros (invierno), con un ritmo que no podemos determinar.

En cuanto a los restos humanos, que aparecieron revueltos con otros restos de fauna y que pertenecían al menos a 5 individuos, es posible que fueran arrastrados por las mismas hienas o los cánidos desde el exterior hasta el yacimiento, ya fueran cazados por los carnívoros o sólo amortizados por los carroñeros. No se documentan en ellos huellas de corte con sílex para hablar de canibalismo y sí una huella circular de cánido sobre una clavícula.

\section{El Ebro como frontera: ¿sois del clan o de los otros?}

La fuerte polémica desatada en toda Europa sobre la transición entre Neandertales y Hombre moderno entre el 40000 y el 30000 ha alcanzado al valle del Ebro, ya que este río ha sido utilizado con frecuencia como referencia de “frontera" (por ejemplo, Zilhao 1993: fig. 7; D'Errico et alii 1998, fig. 9 o Bocquet-Appel y Demars 2000: 550) para separar los elementos residuales neandertales (al Sur) de los recién llegados cromañones (al Norte). En estos últimos años han comenzado a aparecer fechas muy antiguas para "cromañones" peninsulares: Arbreda, Romaní, Castillo y, con aguda crítica por parte de Fortea, La Viña, alcanzan cifras en torno al 40000-35000 BP para las capas más antiguas de sus depósitos auriñacienses (Delibrias et alii 1987; Cabrera y Bischoff 1989; Fortea 1995; Cabrera et alii 1996; Rink et alii 1996), los cuales contrastan con las fechas obtenidas en yacimientos musterienses de Andalucía o Portugal, posteriores al $35000 \mathrm{BP}$ estando situadas la mayoría en torno al 30000. Así las recientes del Boquete de Zafarraya (Barroso y Hublin 1994), las clásicas de Carigüela (Vega 1993), Cova Negra (Villaverde y Fumanal 1990) y Beneito (Iturbe y Cortell 1992)) y las portuguesas de Lapa dos Furos, Foz do Enxarrique, Figueira Brava, Pedreira Salemas, Columbeira, Caldeirao y Conceiçao (Bicho 2000). Esta coexistencia en el tiempo de hombre de Neanderthal y Hombre Moderno ha abierto una discusión que se ha plasmado en la celebración de varios congresos sobre el tema (Madrid, Capellades, Gibraltar, Foz Coa o Lieja) pero, como veremos, habrá que eliminar la "frontera del Ebro" como límite (río perfectamente vadeable a pie en verano), ya que existen entre 40 y 35 Ka musterienses al Norte (Ermitons y Roca dels Bous, por ejemplo) y quizá auriñacienses al Sur (Peña Miel) . La fecha de 37 Ka que entregó esta cueva para el nivel c habrá que contrastarla con una datación directa de la azagaya de la excavación Lartet para averiguar si los materiales auriñacienses de la cima del nivel se han introducido en un depósito musteriense previo desde un posible nivel superior desaparecido por la erosión. Como señala G. Vega en su comentario al artículo de D’Errico, el Ebro es sólo una frontera más de las muchas que tuvo el auriñaciense en su expansión por la Península.

En Navarra, la sorprendente cueva de Abauntz ha entregado en la campaña de 1995 un nivel, el "h",. a $5 \mathrm{~m}$ bajo la línea cero. Está constituido por limos de color marrón, con un nivel de piedras angulosas de tamaño medio y grande que lo cierran y separan de los niveles superiores. Ofrece gran cantidad de restos 
de fauna muy bien conservada, 2867 huesos reconocibles, la mayoría de oso de las cavernas (1564 restos), animal del que se han recuperado varios cráneos. Existen otros carnívoros como zorro (63 restos), lobo (43), hiena (19), Panthera pardus (15) y mustélidos (6). Entre los ungulados aparecen ciervos (65 restos), sarrios (37), cabras (6), Bos/bison (8), reno (1) y caballo (Equus gallicus: 1). A reseñar que los restos de oso no presentan ninguna marca de actividad antrópica, por lo que cabe pensar que su presencia en la cueva no tuvo relación con el hombre sino que sería su cubil de invierno.

Esta fauna se encuentra asociada en estratigrafía a una industria lítica de la que se recuperaron 2 bifaces (amigdaloide corto y protolimande) y 11 hendedores, (dos de ellos bastante evolucionados) todos éstos fabricados sobre arcilla carbonatada o cuarcita. Entre las raederas, de gran tamaño y con retoque escaleriforme, predominan las transversales (5) sobre las laterales (2). Sin embargo, junto a estas piezas de aspecto "arcaico" existen otras fabricadas en sílex de muy buena calidad que se adscriben al Grupo Paleolítico Superior: un raspador sobre lámina retocada, un buril diedro, 3 abruptos indiferenciados tipo raclette con todo el contorno retocado y un claro perforador, además de otras piezas comunes como una raedera latero-transversal, un denticulado y 3 lascas retocadas.

No se ha registrado ningún hogar ni tampoco existencia de carbones, aunque sí algunos huesos completa o parcialmente quemados. Llama la atención la presencia de dos lajas calizas verticales con dos cantos rodados calzando una de ellas. A ambos lados se da una notable acumulación de huesos, y, aunque no hay evidencias de combustión a su alrededor, el sedimento aparecía claramente ennegrecido (Mazo y Utrilla 1996).

La datación del nivel "h" por tipología recordaría un Achelense avanzado o un M.T.A., antiguo "vasconiense" tipo Castillo, Morín y Olha, refrendado por la fecha obtenida por AMS en el Laboratorio de Groningen: >45000 BP (GrA 16960) Sin embargo la realizada según la técnica de E.S.R. por Jack Rink sobre dientes de bóvido sorprende con un $30 \pm 5 \mathrm{Ka}$, cuestionable por demasiado reciente, aunque encajaría con los útiles de sílex evolucionados del nivel. Ya hemos citado la polémica de la tardía extinción en la Península de los Neanderthales (cuyos restos humanos, por otra parte, no suelen aparecer asociados a industria de tipo MTA). De aceptarse esta segunda fecha para el nivel "h" de Abauntz, estaríamos en presencia de un nuevo ejemplo de Musteriense tardío al Norte del Ebro.

Mayor problema cronológico plantean los yacimientos oscenses de la Fuente del Trucho y las Fuentes de San Cristóbal . La Fuente del Trucho fue excavado por Anna Mir durante varias campañas, detectando niveles arqueológicos que fueron clasificados sin ninguna duda en el Musteriense, como así parecen reflejar la selección de materiales expuestos en el Museo de Huesca. El problema se presenta al datar por AMS estos niveles ya que las fechas obtenidas en Beta Analytic entregan una cronología del Paleolítico Superior ( $19060 \pm 80$ BP para la unidad superior y $22460 \pm 150$ BP para la inferior). Como comenta la autora "la tipología, materia prima y técnica de talla son más propias del Paleolítico Medio mientras que las estructuras de hábitat, las pinturas rupestres y los grabados se corresponden con la cronología absoluta de las unidades detectadas" (Mir 1998).

Si el material datado procediera de los carbones de los hogares que identificó como de calefacción, cabría suponer que los autores de las pinturas, supuestamente gravetienses (manos y grabados exteriores) y solutrenses (quizá caballos ) excavaron hogares a costa de los niveles musterienses, ya sea para calentarse o para iluminar la zona a decorar, y es ese momento, el del arte, el que están datando las fechas. Ahora bien, si las muestras enviadas a datar no proceden de intrusiones de hogares de los autores del arte sino que se hallaran bien sellados en los niveles musterienses (dato que desconocemos) habrá una fuerte contradicción entre industria y dataciones, demasiado recientes para un musteriense, por muy tardío que se presente en el Sur de la Península.

El yacimiento de Las Fuentes de San Cristóbal, (FSC) en el Isábena, acaba de ser excavado en tres campañas realizadas por un equipo de gentes formadas en la Universidad de Tarragona. Ha entregado una secuencia estratigráfica residual, adosada a la pared y semidestruida por la carretera que la corta. Contiene 9 niveles arqueológicos que se adscribieron a la cultura musteriense pero que, a juzgar por lo publicado en el 
Congreso de Vilareal (Rosell et alii 2000), no aportan suficiente documentación para ser clasificados, ni por tipología ni por dataciones absolutas. Así, traduciendo al lenguaje tipológico clásico la citada publicación, sólo se han recogido escasas lascas retocadas, mientras que en la fauna, de esquirlas muy fragmentadas, solo se han reconocido un fragmento de molar de ciervo y otros dos restos de équido.

Las dataciones por AMS, han permitido conocer la cronología de los niveles superiores, englobados entre un 20220 \pm 380 del nivel M; 27.200 para el nivel O y un 36000 \pm 1900 para el nivel P, es decir, una cronología Paleolítico Superior en los dos primeros casos, tal como ocurrió en Fuente del Trucho. En cuanto al tercer nivel, el P podría englobar la lista de los musterienses tardíos, al igual que el nivel R3 de la Roca dels Bous, en el Segre, con sus 38800 BP o el nivel a de Gabasa, con >39900 BP, ambos próximos al yacimiento citado.

Estos cinco yacimientos, Gabasa, Roca dels Bous, Abauntz, Fuentes de San Cristóbal y Fuente del Trucho, todos ellos en el Prepirineo y por tanto al Norte del Ebro, entregan fechas para niveles musterienses posteriores al 40000. De ellos, los dos primeros entran en cronología ortodoxa para un musteriense, aunque conviviendo con otras fechas catalanas del hombre moderno como Romaní, Reclau Viver, Mollet y Arbreda (Maroto et alii 1996); el tercero (Abauntz) presenta un margen de 5000 años que lo acerca a la normalidad (aparte de la fecha de AMS que parece más fiable) y los dos últimos deben quedar como muy cuestionados, salvando la fecha del 36000 de FSC que sería aceptable para un musteriense pero del que no se posee todavía cultura material.

También habría que citar la fecha de 31100 550 (OxA-4603) del nivel 5a y b de la cueva de La Ermita, en el Arlanza (Burgos), demasiado reciente para sus excavadores (Moure et alii 1997) pero que no desentona en el conjunto de fechas musterienses "al sur del Ebro". También las fechas de la atípica cueva dels Ermitons, en la Garrotxa prepirenaica, de 36430 \pm 1800 BP (CSIC 197) y 33190 \pm 660 BP (OxA-3725) documentan de nuevo un momento tardío del Musteriense, en este caso al Norte del Ebro, si bien debe reseñarse la presencia importante de útiles progresivos para un musteriense ( 3 buriles, 7 raspadores y 14 abruptos) y la pésima materia prima que utilizan como soporte que pudo condicionar la fabricación de determinadas piezas (Maroto, Soler y Fullola 1996).

Los "otros", las gentes del Paleolítico Superior Inicial, están representados por 5 yacimientos en el valle del Ebro: la ocupación auriñaciense de la parte superior del nivel c de Peña Miel, en la Rioja, datada en $37700 \pm 1300$ (OxA- 5518); el nivel gravetiense del abrigo de Ángel en Ladruñán (Teruel) que acabamos de excavar en el verano del 2000 y que ha sido datado en 25330 $190 \mathrm{BP}$ (GrA: 16961) y tres yacimientos en Navarra: el de superficie de Mugarduia Sur, en la Sierra de Urbasa, un lugar de talla al aire libre que entrega materiales de tipo gravetiense (puntas de dorso) pero que carece de dataciones absolutas; el de la cueva de Alkerdi donde un sondeo del vestíbulo ha entregado un nivel 2 con una gran punta de dorso, datado en 26470BP (GrN20322) (Barandiarán 1993b) y el nivel IIb am. de Zatoya con un nivel amarillo como el de Ángel que acaba de ser datado en 28870+760-690 BP (GrN 23999) (Barandiarán y Cava e.p.).

De los tres sólo el nivel c de Peña Miel entra en la polémica de la frontera, ya que se halla en el Iregua, al Sur del Ebro. Se trata de un nivel muy pobre, con lascas de cuarcita similares a las de los niveles musterienses, que, en su parte alta se encuentra ocupado por unas gentes que aportan raspadores carenados de sílex, láminas retocadas y algún buril. La muestra de hueso se tomó de esta parte superior, en contacto con los raspadores y láminas citados, pero no podemos tener la certeza de que el hueso no fuera incorporado del material musteriense subyacente. Las fechas han sido referidas por Hedges y Pettitt (1998) en el Coloquio de Lyon, pero la discusión de su posición estratigráfica debe verse en el de Foz Coa de 1998 (Montes, Utrilla y Hedges 2001). Más datos sobre Peña Miel en nuestra revisión del concepto “frontera del Ebro" presentado al Congreso de Lieja (Utrilla, Montes y González e.p.).

En cuanto a la fecha del abrigo de Ángel, procedente de un nivel de talla con varios buriles nucleiformes, debe destacarse su proximidad con otras portuguesas aceptadas, como Caldeirao (27600) y Conceiçao (27200) que entregan materiales musterienses. Un caso distinto es la sepultura de Lagar Velho, clasificada en el 
gravetiense antiguo y datada en 24.860, que ha entregado restos humanos de un niño, al parecer descendiente de antiguas mezclas de neanderthales y cromañones (Duarte et alii 1999).

Destaquemos también la existencia en el río Mijares (Roca Hernando, en Cabra de Mora) de una roca vertical, exenta, totalmente grabada con surcos de trazo profundo y tendencia animalística, donde es posible individualizar una cabeza de ciervo o uro y algunas figuras de cuello largo incompletas. Recuerda los santuarios exteriores del Paleolítico Superior Inicial de la Costa Cantábrica y el panel de los grabados exteriores de Fuente del Trucho, por no citar la emergencia de formas que aparece en los contornos inacabados de Altamira, Gargas, ábside de Lascaux o Trois Freres. Sin embargo no cabe descartar totalmente una cronología posterior en la edad del Bronce ya que los materiales del entorno pertenecen a esta época aunque no encaje en la iconografía propia de la época (Utrilla, Villaverde y Martínez 2001).

\section{Abauntz, una cueva bien organizada}

El nivel e, Magdaleniense Medio-Superior, datado en 13500 BP y situado al final del Dryas Inferior, es el más interesante de la amplia secuencia estratigráfica de la cueva de Abauntz. Fue excavado en su totalidad, ya que la cueva está pendiente de ser anegada por un embalse, de los muchos previstos en el Prepirineo ${ }^{5}$. Tiene la ventaja de representar una ocupación efímera, probablemente veraniega, según los estudios de arqueofauna de Altuna y Mariezcurrena y que apenas ha sido alterada por actividades postdeposicionales, según nos confirmó M. Hoyos en repetidas visitas al yacimiento.

Ello nos ha permitido encontrar un espacio medianamente ordenado que nos facilita realizar estudios microespaciales, que, completados por los traceológicos de C. Mazo y palinológicos de P. López, nos han llevado a identificar un área de talla en la boca de la cueva y un hogar en el interior de la primera sala, en torno al cual se efectúan las siguientes actividades (Utrilla y Mazo 1992):

- Raspado de pieles, documentado por una concentración de raspadores y buriles sobre truncadura, los cuales presentan esta zona, la del retoque abrupto, como parte activa, y con el mismo tipo de huella de raspado de pieles y en la misma posición ladeada que el frente de raspador.

- Perforado de pieles, contiguo al anterior, presentaba asociación de perforadores y buriles diedros, ambos con idénticas huellas de rotación sobre las pieles. La concentración de ocres rojos en la zona pudo prevenir su descomposición ${ }^{6}$.

- Área de descanso, al fondo, en la zona más resguardada de las corrientes de aire, con una ausencia total de piezas líticas. Allí las concentraciones de polen marcan un porcentaje excepcional de helechos y juncáceas que serían utilizados como base vegetal de lechos (Utrilla, López y Mazo 1986)

- Restos de comida abundan en torno a las piedras del hogar, por lo que habrá que suponer las habituales actividades de mantenimiento alrededor.

5. Varios embalses en curso de realización o los previstos en el PHN inundarán cuevas y abrigos prehistóricos situados en lugares estratégicos: así el de Arraiz anegará Abauntz, el de Rialp la cueva del Segre, el de Pontet el abrigo del mismo nombre y la Cueva Ahumada. El yacimiento musteriense del Estret de Tragó ya se encuentra bajo las aguas del Embalse de Sta Ana en el Noguera Ribagorzana.

6. Es muy interesante el concurso de la traceología para identificar adecuadamente la función de estas asociaciones. En la memoria de las cuatro primeras campañas (Utrilla 1982) ya había detectado la asociación raspador-buril sobre truncadura y perforadoburil diedro pero no pudo ser interpretado hasta que Carlos Mazo identificó huellas idénticas en los útiles asociados. Es más, yo interpreté erróneamente la concentración de buriles diedros y ocres como una actividad "artística" de pintar y grabar (buriles) cuando éstos habían sido usados para el perforado de las pieles. 
En las campañas de 1991 a 1995 hemos excavado una segunda sala (donde termina la ocupación magdaleniense) y el estrecho corredor que la une con la primera. En ellos hemos localizado dos nuevos hogares: uno en el corredor, adosado a la pared y que interpretamos como de iluminación, y otro en la segunda sala, en torno al cual (y en el corredor) se han encontrado la mayoría de las varillas y azagayas del yacimiento. La industria lítica, mucho menos abundante, entrega fundamentalmente láminas con huellas de uso y algunos buriles. He supuesto una utilización de las láminas en una actividad de aguzado de las armas de caza (azagayas y varillas) pero no ha sido confirmado por un estudio traceológico ya que las piezas presentan una pátina brillante del sedimento (muy húmedo) que impide ver con claridad la actividad realizada. La distribución de tareas en la superficie del yacimiento ocupada por los magdalenienses documentaría las siguientes actividades:

- En la boca de la cueva y en el pasillo de entrada se efectuaría la actividad de talla, quizá masculina, dada la abrumadora presencia de restos de talla en los cuadros de esta zona

- En el hogar más próximo a la luz de la primera sala estaría el área de trabajo, fundamentalmente femenino por etnología comparada, que se centraría en actividades de subsistencia (cocina) y de trabajo de las pieles (raspado y perforado).

- En la segunda sala, ya sin luz natural, se situaría el dormitorio o área de descanso. Las armas aparecían concentradas (¿apiladas contra la pared?) en ambos extremos de una posible plataforma de madera marcada por ocho agujeros de poste alineados y emparejados, los cuales pudieron sujetar alguna estructura que les protegiera de la humedad y regularizara la pendiente descendente de la segunda sala. La escasez de utillaje lítico en esta zona abundaría en esta interpretación, pudiendo atribuirse la presencia de dos hogares (uno en el corredor y otro en la segunda sala) a una función de calefacción. Por otra parte la existencia de cinco huesos de saiga en esta zona (falanges y un tarsal) pudiera indicar la presencia de pieles de animales especiales procedentes de Aquitania (no se ha documentado la saiga en España) que concordarían con el área de descanso propuesta para esta sala.

Una representación en planta de estas actividades puede verse en Utrilla y Mazo (1992: fig. 4) para la primera sala y en Mazo y Utrilla (1996: figs. 3 y 4) para las estructuras de la segunda.

\section{Se acaban las ciervas: busquemos nuevos cotos de caza}

Bajo este epígrafe queremos reseñar como, tras la sobreexplotación ${ }^{7}$ de los cérvidos que tuvo lugar en la Costa Cantábrica durante el Magdaleniense Inferior (que ya fue señalada por Altuna, Straus, Freeman y en cierto modo Clark en sucesivos artículos) las gentes magdalenienses, que han aumentado considerablemente su población a juzgar por la multiplicación de yacimientos en la Costa Cantábrica, se ven obligadas a diversificar su dieta con aprovechamiento de otros ungulados y recursos marinos, al mismo tiempo que se colonizan los valles del interior y se mejoran en efectividad los utensilios de caza (González Sainz 1989: 181). Es en estos momentos del Magdaleniense Medio y comienzos del Magdaleniense Superior, en torno al 13000 BP, cuando los cazadores de la Costa Cantábrica o los del Pirineo Francés exploran nuevos territorios de caza, encontrando en los barrancos escarpados del Prepirineo el lugar ideal para la caza intensiva de la cabra ${ }^{8}$ y el conejo y, en menor medida, de ciervos y sarrios.

7. El caso límite se da en el nivel VII de Ekain, donde Altuna y Mariezcurrena (1984) han documentado la caza especializada de cervatillos de pocos meses de vida, acudiendo los cazadores al prado donde se retiran las ciervas para parir a sus crías

8. En efecto, los estudios faunísticos de Pedro Castaños (1993) revelan que los restos de cabra suponen en Chaves el $85 \%$ de los ungulados cazados en el nivel $2 \mathrm{~b}$ y el $90,3 \%$ en el nivel $2 \mathrm{a}$, quedando un $8,6 \%$ para el sarrio en el nivel $2 \mathrm{~b}$ y un $1,8 \%$ en el $2 \mathrm{a}$. Escasos restos de ciervo (6\% en 2 b y 5,6\% en 2a) completan el espectro de los ungulados cazados. La dieta animal se complementaba con el consumo de conejos, muy abundantes en el yacimiento y que recuerdan patrones de consumo de cuevas mediterráneas. 


\section{La ocupación del Prepirineo por los magdalenienses}

Los precedentes de gentes paleolíticas en el Prepirineo los conocemos a través de las pinturas de la Fuente del Trucho, datables en un gravetiense (manos) o solutrense (caballos), con convenciones típicas del estilo II de Leroi Gourhan (curva cérvico-dorsal muy marcada, falta de detalles en el interior de las figuras) y del Solutrense Medio de Parpalló, como las patas curvadas hacia adentro en líneas paralelas abiertas (Villaverde 1994). Sin embargo algunos caballos presentan detalles de despiece, (como la crinera muy marcada con rayas verticales, ojo y boca señalados) que recuerda ejemplos del estilo III como Pasiega y Covalanas.

Los primeros yacimientos datados por C14 o por tipología pertenecerán a una etapa tardía, del Solutrense Superior, coincidiendo con la supuesta mejoría climática del Interestadio de Laugerie, aunque está muy contestada la existencia real de periodos templados en esta época (Sánchez Goñi 1993). Nos referimos al nivel de puntas de escotadura de tipo mediterráneo, no asociadas a puntas de pedúnculo y aletas de retoque plano, de la cueva de Chaves que, con un 19700 \pm 310 , nos indica una influencia del salpetriense inferior, del Gard francés, y no tanto del Levante español, donde estas puntas son más tardías. En efecto, tal como hemos publicado (Utrilla y Mazo 1994) los datos tipométricos de las escotaduras encajan perfectamente con los del nivel inferior de Salpetrière (con quien coinciden también las fechas c14, de 19530 \pm 270 ) y no tanto con los ejemplos levantinos de Parpalló, Mallaetes o Ambrosio. Estaríamos en presencia de los primeros contactos documentados del Prepirineo con la zona mediterránea francesa, algo que será habitual en el Epipaleolítico y Neolítico.

En cuanto a la navarra cueva de Abauntz, su nivel solutrense superior (con puntas de muesca de retoque plano) documenta mejor las relaciones con Aquitania (Azkonzilo, Isturitz o Brassempouy) y con la Costa Cantábrica (Aitzbitarte y Amalda, como yacimientos más próximos), relación que podría asignarse también a la cantera de Coscobilo. En cambio el yacimiento de Leginpea en Echauri, en plena zona llana de la Cuenca de Pamplona, presenta algunas puntas de escotadura de tipo mediterráneo.

El Dryas antiguo está representado por el nivel e de la cueva de Abauntz. Este yacimiento, datado finalmente en $13500 \pm 160 \mathrm{BP}$, entrega una industria ósea decorada con motivos similares ${ }^{9}$ a la de los yacimientos del Magdaleniense Medio-Superior, ya sean asturianos como Caldas VIII, La Viña IV inf, Llonín IX o Tito Bustillo Ic o vascos como Isturitz, Duruthy, Santimamiñe, Bolinkoba y Ermittia (Utrilla 1995). También se adscribe a esta época el abrigo de Forcas I, en Graus, en sus niveles XV (con abundantes raspadores nucleiformes que recuerdan el componente industrial del Magdaleniense Inferior), XVI y XVII que no han podido ser datados por ausencia de materia orgánica. Al mismo periodo habrá que referir el nivel g de Berroberría (14430 \pm 290$)$ y los niveles inferiores de la cueva del Parco, en la que sólo se ha efectuado un sondeo. Son el

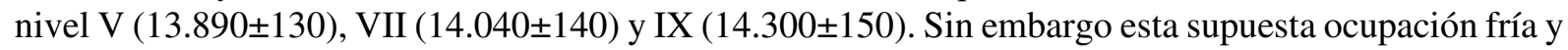
seca de carácter estépico que denotan las fechas de Parco no coincide con el estudio sedimentológico de Mercé Bergada que ve características templadas en los niveles inferiores, VII a IX (Fullola et alii 1999) ${ }^{10}$.

9. Así las espátulas con grabados escaleriformes en retícula presentes en Llonín, Isturitz y Duruthy; o el cincel con series verticales en "V" en relieve, similares a otras de Caldas e Isturitz; o los rombos dobles con trazo vertical interior que existen también en Bolinkoba, Santimamiñe, Ermittia, Isturitz, Paloma o Cueto de la Mina o varillas con series de paréntesis invertidos que asemejan representaciones frontales de patas de herbívoros, presentes también en Caldas e Isturitz

10. En la secuencia de Forcas I los niveles XVI y XVII fueron caracterizados por Fumanal y Ferrer (inédito) como templados y húmedos y adscritos en principio al clásico Anglés y a la posible interfase Cendres D. Esta sin embargo todavía no ha sido contrastada por la excavación de Villaverde, quedando sólo esbozado el hiatus entre la fase E de Malladetes y la C de Cendres, debido a la ausencia de datos paleoambientales y cronoestratigráficos del Magdaleniense Inicial de Parpalló (Villaverde, Aura y Barton 1998: 128, tabla I). No hay que descartar por otra parte que tanto en Forcas, como en Parpalló y Cendres estemos ante un Laugerie-Lascaux, la Interfase D de Fumanal, dado que no sabemos la duración del hiato. Sólo admitiendo las mejoras climáticas de Prebolling o Anglés podría explicarse el carácter templado de los niveles inferiores de Parco pero no parece que estas oscilaciones estén generalizadas, ya que Hoyos (1995) sólo encuentra Anglés (15.200-14.700) en la Costa Cantábrica, mientras que Laville sólo documenta el Pre-bölling (hacia 14.500-14.000) en el Sudoeste de Francia (Delpech et alii 1994). 
Recientemente se ha localizado el yacimiento de Montlleó, cerca de Andorra y a $1.130 \mathrm{~m}$ de altitud que ha entregado una fecha de $15440 \pm 40 \mathrm{BP}$ para un nivel con triángulos escalenos, clasificable en un magdaleniense inferior, en una supuesta época fría, sorprendente para una zona tan alta. El que estuviera practicable el paso de la Cerdaña durante el Magdaleniense explicaría la fácil relación con Francia a través del valle del Segre-Cinca (Fullola e.p.).

La mejoría climática de la oscilación de Bölling (o mejor Interestadio del Tardiglaciar), bien detectada en el Pirineo español por los estudios de Montserrat (1992: 94) sobre los ibones de Búbal y Tramacastilla y en el Pirineo francés por los de Jalut (1992: 136), marcando ambos un aumento inusitado de Juniperus, pudo favorecer la expansión de los magdalenienses por las Sierras Exteriores prepirenaicas . Esta ocupación aparece refrendada por las dataciones absolutas de los primeros asentamientos magdalenienses del Prepirineo oscense: $12950 \pm 70$ en el nivel $2 b$ de Chaves, seguido del $12660 \pm 70$ y $12020 \pm 350$ del nivel $2 \mathrm{a}$ y por el $13010 \pm 320$ del nivel 14 de Forcas I, seguido del $12620 \pm 380$ del nivel 13, todos en fechas BP. Similares fechas entregan la cueva del Parco, en el Segre (13070 \pm 140 BP para el nivel III) y la conocida Bora Gran d'en Carreres, en Gerona que ha aportado fechas similares para un diente de reno: $13080 \pm 90$ BP y $12830 \pm 80$ BP (Fullola e.p.).

En Navarra estaría representado en el nivel "e" de Berroberría (13270 \pm 220$)$ y en Zatoya por el nivel IIb, datado en $12205 \pm 90$ BP y el II, con tres fechas en torno al 11500 BP(Barandiarán y Cava e.p.). Similar cronología presenta el nivel "e1" (2r) de la cueva de Abauntz, datado en 11760 90 BP, que ha entregado los más bellos ejemplos de arte mueble sobre piedra hallados en estos últimos años. Se trata de tres bloques de caliza margosa en los que se representan en el bloque 1 ciervos de frente y de perfil, cabras en fila y en posición frontal, un antropomorfo y varios terneros (anverso) y una cierva completa en la cara inversa. En el bloque 2, con una superficie cóncava con cazoleta que sirvió como lámpara, se representan un caballo entero, 4 cabras de frente y un posible antropomorfo. En el bloque 3, de forma apuntada, aparece una de las más bellas cabezas de caballo del arte paleolítico, de $17 \mathrm{~cm}$ de longitud, con combinación de trazos de buril de filo simple y múltiple. Las convenciones estilísticas (realismo en los detalles, cabras y ciervos en posición frontal) coinciden con las generalizadas en el Magdaleniense Final (Pendo, Urtiaga, La Vache) (Utrilla y Mazo 1996b). Fechas similares ha entregado la excavación Fullola de la cueva del Parco para unos niveles de características microlaminares, el Ib: $11430 \pm 60$ BP y el Ic: $11270 \pm 90$ BP (Fullola e.p.).

\section{La ruta del Jalón hacia la Meseta: los yacimientos magdalenienses del valle del Henar}

Aunque el valle del Jalón es un corredor natural de acceso a la Meseta Sur, enlaza también con la Meseta Norte, a través de su afluente el Henar, que penetra en la provincia de Soria hasta alcanzar la cuenca de Almazán, lugar donde se había documentado la única pieza del Paleolítico Superior de la zona, la placa grabada de Villalba (Jimeno et alii 1990). Sin embargo el reciente descubrimiento de un arpón magdaleniense de una fila de dientes en la cueva Bolichera de Calcena (Zaragoza), en el piedemonte del Moncayo y a 900 metros sobre el nivel del mar), nos indica que debieron ser varias las rutas de comunicación con la provincia de Soria, siguiendo distintos afluentes del Jalón en su margen izquierda (Millán et alii 1999).

\footnotetext{
Conocida es por otra parte la polémica entre la interpretación de los resultados palinológicos de determinados yacimientos en cueva (periodizaciones clásicas de Leroi Gourhan o Boyer Klein) y los procedentes de lagos y turberas (con confirmación en las secuencias de las calotas glaciares) que eliminan todos los interestadios entre el 40.000 y el 14.000 y la fase fría del Dryas II, con un Interestadio del Tardiglaciar que abarcaría las tradicionales Bolling-Allerod sin pusación fría intercalada. Los últimos artículos de revisión para la zona mediterránea que aún entran en polémica pueden verse en las Actas del coloquio de Carcassonne (Burjachs in Fullola et al. 1999 frente a Sánchez Goñi 1993 y 1999). De cualquier modo el supuesto interestadio de Anglés se encajaría en una fase general fría del Dryas I, entre el Cantábrico III y V de Hoyos, por lo que no nos plantea mayor problema la aparente diferencia climática de ambas secuencias.
} 
La comunicación con la Meseta Sur remontaría el valle del Jalón hasta alcanzar las altas cuencas del Henares y del Jarama, siguiendo aproximadamente el trazado de la actual línea férrea. Midiendo la distancia en línea recta desde los yacimientos magdalenienses de Cetina existen unos $60 \mathrm{Km}$ hasta los grabados paleolíticos de las cuevas de Los Casares y la Hoz y unos 100 del conjunto paleolítico superior del alto Sorbe, con el yacimiento de Peña Capón como más representativo de las primeras culturas (Alcolea et alii 1997) y la cueva del Reno como mejor exponente del arte parietal (Alcolea, Balbín, García y Jiménez 1997). Los trabajos de Carmen Cacho en el embalse de Buendía, en el límite entre Cuenca y Guadalajara, completan el panorama de yacimientos paleolíticos en la zona, siendo este último rigurosamente contemporáneo del abrigo Vergara de Deza (Cacho y Pérez 1997).

El abrigo de la Peña del Diablo de Cetina (Zaragoza) fue excavado por P. Utrilla durante los años1994 y 1995, entregando tres niveles fértiles de similares características. Se recogieron en total 4.145 restos de talla (lascas, láminas y núcleos) siendo 146 las piezas retocadas. Por tipos primarios destacan los buriles, con 52 ejemplares, seguidos de las hojitas de dorso (50) y los raspadores (28). Los índices del conjunto son los comunes a todas las industrias magdalenienses de la zona: 19,1;35,6; 34,2 para el IG, IB y GP respectivamente, con una factura tan cuidada que encaja perfectamente en una cultura Magdaleniense Final de tipo clásico, a pesar de que su fecha se acerca más al Aziliense (10760 140 BP para el nivel 2). La fauna se limita a 10 fragmentos de dientes de caballo, un animal muy apropiado en una zona de acceso a la alta y fría estepa castellana.

Situado en el mismo paleocanal donde se ubica la Peña del Diablo 1 localizamos un yacimiento al aire libre que denominamos Peña del Diablo 2, a 100 metros más adelante del anterior, bajo lo que pudo ser un abrigo desmoronado que hoy no se conserva. Poseía un nivel de ocupación adscribible en principio a la misma época magdaleniense que el yacimiento contiguo, entregando como materiales más significativos algunas hojitas de dorso, 2 raspadores sobre lámina y 1 buril sobre truncadura cóncava (Utrilla 1997c).

Los abrigos denominados "Vergara" y "Alejandre" se encuentran en el término municipal de Deza (Soria) a pocos kilómetros de Cetina sobre la margen izquierda del río Henar. El abrigo Vergara fue excavado por Utrilla y Blasco en dos campañas de 1996 y 1997, mientras que en Alexandre sólo se ha realizado un sondeo estratigráfico debido a la dureza del sedimento. La industria lítica del abrigo Vergara en su nivel d, adscribible a un Magdaleniense Inferior (14000 BP), es la típica de un lugar de talla ya que entrega 6.100 efectivos no retocados, con 3.106 microlascas y 1.772 microláminas para $2 \mathrm{~m}^{2}$ excavados. Las piezas retocadas son 137 , destacando los buriles (33 ejemplares, 12 de ellos nucleiformes), las hojitas de dorso (59) y los raspadores (11). Abundan las hojitas de retoque semiabrupto que en lugares del Magdaleniense Inferior como Erralla han sido clasificadas como próximas a las laminitas Dufour. No parecen un subproducto de talla ni de huellas de uso, tal como nos han señalado tecnólogos (M. Aguirre) y traceólogos (C. Mazo). Un avance cronoestratigráfico y climático de los abrigos del Henar ha sido publicado en el homenaje a Pilar Fumanal (Utrilla et alii 1999) mientras que el estudio arqueológico se halla en prensa en el Boletín del seminario de Arte y Arqueología de Valladolid (Utrilla y Blasco e.p.).

La primera fecha documentada acerca de la ocupación magdaleniense del Henar se sitúa en el 15370 \pm 110 $\mathrm{BP}$, en el nivel IIIb del abrigo Alejandre, correspondiente en la secuencia clásica a la supuesta fase templada de Anglés. Correspondería a la fase Cantábrico IV de Hoyos, que califica como "fresca" (aunque más fría que el clima actual). En la secuencia mediterránea de Fumanal esta cronología coincide en cambio con la fase E, una pulsación fría que se refleja en Tossal de la Roca IV (15360 BP) o Matutano XIII.

Durante una fase más avanzada del Dryas I tiene lugar la ocupación del nivel d de Vergara, datado en el 14000 BP y caracterizado por un clima frío que quedaría refrendado por las plaquetas de gelifracción del nivel d1, siendo el nivel d2, de limos y cantos angulosos, algo menos frío. Podría corresponder a la parte superior del nivel III de Alejandre. Es la fase Cantábrico V de Hoyos, de frío intenso en el 14000, y la fase Cendres $C$ de Fumanal, que correspondería a los niveles XI de Cendres y XV a y XV b de Forcas I, característicos éstos por su industria de un Magdaleniense Inferior Cantábrico de tipo Juyo. 
La siguiente ocupación magdaleniense del Henar respondería a un momento de mejoría climática que inaugura el Interestadio del Tardiglaciar a partir del $13000 \mathrm{BP}$. Ciertos ecos de ésta parecen quedar reflejados en las muestras de polen pertenecientes al nivel 3 de Peña del Diablo: un avance de especies arbóreas (entre ellas Pinus, Juniperus y Betula ) determinarían unas condiciones climáticas menos extremas. A esta etapa climática templada correspondería la Interfase $F$ de Fumanal (Interfase B de Cendres II) representada también en Tossal III, Matutano XII y probablemente Forcas XIII a XI.

La llegada de la fase fría del Dryas Reciente aparece en el nivel 2 de Peña del Diablo, refrendada por la fecha de 10760 BP y por el polen de la muestra 9 que marca un fuerte retroceso arbóreo en la proporción AP/NAP. Un espectro palinológico más o menos similar entregan las muestras 6 y 7 del Abrigo Vergara, lo que unido al estudio sedimentológico que señala un $14 \%$ de plaquetas en b1 y la existencia de cantos con gravas angulosas nos llevan a proponer un clima poco frío (Utrilla et alii 1999).

\section{La ruta hacia Levante: el camino Guadalope-Mijares}

Hemos visto como a principios del Paleolítico Superior se hallan gentes tallando en el abrigo de Ángel, en el alto Guadalope-Maestrazgo y quizá otros dejando su arte (Roca Hernando) en el valle del Mijares, que enlaza con el anterior a través del río Pitarque. Esta ruta hacia Levante por el Maestrazgo (al parecer más idónea para un cazador que la que sigue la actual carretera general) debió frecuentarse también en el Solutrense o Magdaleniense, a juzgar por los grabados finos de trazo múltiple que aparecen en dos ciervos del barranco Hondo de Ladruñán. Estas características técnicas no coinciden con la ocupación gravetiense del abrigo de Ángel ni con las convenciones del arte levantino, nunca grabado (Utrilla y Mazo 1994), por lo que habrá que suponer una presencia paleolítica más avanzada en la zona, quizá durante el magdaleniense que pudiera rastrearse en un nivel residual adosado a la pared (10 superior) del abrigo de Ángel cuya datación esperamos.

En cuanto al nivel a2 de la cueva de Los Toros de Cantavieja (que no pudo ser datado por falta de materia orgánica) sólo podemos constatar su no pertenencia a los niveles musterienses que le subyacen, dada la existencia de hojitas de dorso, raspadores y algún buril. Esta industria encaja mejor en una cultura Paleolítico Superior o, menos probable, Epipaleolítico microlaminar, que no difiere en el Valle del Ebro de un aziliense tardío.

En resumen, observamos en estos últimos años un intento de interpretar los asentamientos bajo un influjo de la arqueología anglosajona, patente en la vertiente socioeconómica y funcional de la investigación. Así han aparecido los estudios traceológicos (C. Mazo y R. Domingo), tafonómicos (F. Blasco) o microespaciales, que en nuestro caso se aplicaron al magdaleniense de la cueva de Abauntz (Utrilla y Mazo 1992) al musteriense de Gabasa y Peña Miel (Blasco, Montes y Utrilla 1996) y que están dando buenos resultados en la cueva de Chaves, todavía en curso. La escuela clásica francesa, basada en la cronoestratigrafía climática, perdurará en los estudios sedimentológicos (a cargo de Pérez González, Peña, Bergadá, Hoyos o Fumanal), paleontológicos (J. Altuna, P. Castaños y K. Mariezcurrena) y palinológicos (a cargo de Pilar López y Penélope González, quien abrirá nuevas líneas como el estudio de palinofacies o el análisis del polen a través de los coprolitos de Gabasa). Quedan pendientes los estudios tecnológicos y de materias primas, tan queridos por nuestros colegas franceses, con alguna aproximación de Ángeles Tilo en Aragón, una Tesis Doctoral en Cataluña de Elisa Domenech y otra en el País Vasco de Andoni Tarriño. Los arqueólogos "no especializados" seguimos con el trabajo de campo y nuestras aburridas tipologías, a las que intentamos darles un nuevo aire con el concurso de la estadística. Queremos aprehender al escurridizo hombre paleolítico bajo todos los prismas posibles, evitando quedarnos en una mera enumeración tipológica-estratigráfica. Pocas veces podemos conseguirlo. 


\section{BIBLIOGRAFÍA CITADA}

ALCOLEA, J. et alii. (1997): “Avance al estudio del poblamiento paleolítico del Alto Valle del Sorbe (Muriel, Guadalajara)", II Congreso de Arqueología Peninsular t. I: 201-218.

ALCOLEA, J; BALBÍN, R; GARCÍA, J.A. y JIMÉNEZ, P.J. (1997): "Nuevos descubrimientos de arte rupestre paleolítico en el Centro de la Península Ibérica: La cueva del Reno (Valdesotos, Guadalajara)", II Congreso de Arqueología Peninsular t. I: 239-257.

ALTUNA, J. (1987): "Fauna de macromamíferos", en P. Utrilla et alii: La cueva de Peña Miel (Nieva de Cameros, La Rioja). Excavaciones arqueológicas en España 154: 103-108. Madrid.

ARMENDÁRIZ, J. (1998): "Hallazgo de dos nuevos bifaces paleolíticos en el valle del río Ega", T.A.N. 13 (1997-1998): 349-357.

BARANDIARÁN, I. (1987): "Manipulación y uso de restos óseos" en P. Utrilla et alii: La cueva de Peña Miel. Nieva de Cameros, La Rioja. Excavaciones arqueológicas en España 154: 87-101.

(1993a): "El lobo feroz: la vacuidad de un cuento magdaleniense", Veleia 10: 7-37. Vitoria.

(1993b): "Los establecimientos de cazadores de la Prehistoria de Navarra. Del Paleolítico medio a inicios del Neolítico", Cuadernos de Prehistoria de la Universidad de Navarra, 3: 53-84. Pamplona.

BARANDIARÁN, I. y CAVA, A. (e.p.): "El Paleolítico superior de la cueva de Zatoya (Navarra). Actualización de datos en 1997", T.A.N. 15. Pamplona.

BARANDIARÁN, I. y VALLESPÍ, E. (1984): "Prehistoria de Navarra”, T.A.N. 2. Pamplona.

BARROSO, C. y HUBLIN, J.J.(1994): “The Late Neanderthal site of Zafarraya (Andalucía, Spain)”, Gibraltar during the Quaternary. AEQUA Monografías, 2: 61-70. Sevilla.

BICHO, N.F. (2000): "Revisao crítica dos conhecimentos actuais do paleolítico Superior português. Paleolítico da Peninsula Ibérica”, Actas del III Congreso de Arqueología Peninsular: 425-442. Vilareal.

BINFORD, L.R. (1988): En busca del pasado. Ed. Crítica. Barcelona.

BLASCO, F.; MONTES, L. y UTRILLA, P. (1996): "Deux modèles de strategie occupationnelle dans le Moustérien tardif de la Vallée de l'Ébre: Les grottes de Peña Miel et Gabasa", The last neandertals, the first anatomically modern humans: 289-313. Barcelona.

BLASCO, F. (1992): “Tafonomía y Prehistoria. Métodos y procedimientos de investigación”, Monografías Arqueológicas 36. Zaragoza.

BLASCO, F. (1995): "Hombres, fieras y presas. Estudio arqueozoológico y tafonómico del yacimiento del Paleolítico Medio de la Cueva de Gabasa 1 (Huesca)", Monografías Arqueológicas 38: 205. Zaragoza.

BLASCO, F. (1997): "In the Pursuit of Game: The Mousterian Cave Site of Gabasa I in the Spanish Pyrennees", Journal of Anthropological Research 53, number 2: 177-217.

BOCQUET-APPEL, J.P. y DEMARS, J.Y. (2000): "Neanderthal contraction and modern human colonization of Europe", Antiquity 74: 544-552.

CABRERA, V. y BISCHOFF, J.L. (1989): "Accelerator 14C dates for Early upper Palaeolithic (Basal Aurignacian) at El Castillo Cave (Spain)", Journal of Archaeological Science 16: 577-584.

CABRERA-VALDÉS, V.; VALLADAS, H.; BERNALDO DEQUIRÓS, F. y HOYOS GÓMEZ, M. (1996): "La transition Paléolithique moyen-Paléolithique supérieur à El Castillo (Cantabrie): nouvelles datations par le carbone-14", Comptes Rendues de l'Académie des Sciences de París t. 322, série IIa: 1093-1098.

CACHO, C. y PÉREZ, S. (1997): "El Magdaleniense de la Meseta y sus relaciones con el Mediterráneo español: el abrigo de Buendía (Cuenca)", El mon mediterrani després del Pleniglacial (18.000-12.000 B.P.) Col.loqui Banyoles 1995: 263-274.

D’ERRICO, F.; ZILHAO, J.; JULIEN, M.; BAFFIER, D. y PELEGRÍN, J. (1998): “Neanderthal Acculturation in Western Europe?", Current Anthropology 39, Junio.

DELIBRIAS, G.; ROMAIN, O. y LE HASIF, G. (1987): "Datation par la méthode du carbone 14 du remplissage de la grotte de l'Arbreda", Cypsela VI: 133-135. 
DELPECH, F. y RIGAUD, J.Ph. (1974): "Etude de la fragmentation et de la répartition des restes osseux dans un niveau d'habitat paléolithique", en Camps-Fabrer (dir): Premier Colloque International sur l'industrie de l'os dans la Préhistoire: 47-55. París.

DELPECH, F.; LAVILLE, H. y RIGAUD, J.Ph. (1994): "Chronologie et environnement climatique du Paléolithique Supérieur dans le Sudouest de la France", El cuadro geocronológico del Paleolítico Superior Inicial: 173-186. Madrid.

DUARTE, C.; MAURICIO, J.; PETTITT, P.; SOUTO, P.; TRINKAUS, E.; PLICHT, H. y ZILHAO, J. (1999): "The Early Upper palaeolithic Human Skeleton from the Abrigo do Lagar Velho (Portugal) and modern human emergence in Iberia", Proceedings of the National Academy of Sciences 97: 7604-7609.

EISENMANN, V.; ADROVER, R.; MOISSENET, E. y MOURER-CHAUVIRE, C. (1989-1990): "Le cheval de Monteagudo del Castillo (Province de Teruel, Espagne)", Paleontologia i Evolució 23: 239-252. Sabadell.

ESTÉVEZ, J. y VILA, A. (1999): "Piedra a piedra. Historia de la construcción del Paleolítico en la Península Ibérica", BAR International Series 805: 357, fig.: 105. Oxford.

FERNÁNDEZ PERIS et alii. (2000): "Cova Bolomor (Tavernes de la Valldigna, Valencia). Catoscronoestratigráficos y culturales de una secuencia del Pleistoceno Medio", III C.A.P. de Vila Real. vol II: 81-100. Oporto.

FORTEA, J. (1995): “Abrigo de La Viña. Informe y primera valoración de las campañas 1991 a 1994”, Excavaciones Arqueológicas en Asturias 1991-1994: 19-32. Oviedo.

FREEMAN, L.G. (1973): "The significance of mammalian faunas from Palaeolithic occupations in Cantabrian Spain", American Antiquity 38: 3-34.

FULLOLA, J.M. (e.p.): "La recherche sur le Paléolithique Supérieur dans le NE ibérique: la Catalogne (1996-2000)", Bilan Quinquenal. Préhistoire Européenne. Lieja.

FULLOLA, J.M.; BARTROLI, R.; BERGADÀ, M.M.; BURJACHS, F.; MENESES, M.D. y NADAL, J. (1997): "Le Magdalénien ancien en Catalogne: approche à l'étude des couches inférieures de la grotte du Parco (Alòs de Balaguer, La Noguera, Lleida)", en FULLOLA Y SOLER eds., El món mediterrani després del Pleniglacial (18000-12000 BP): 303-319, fig.: 6. Girona.

FULLOLA, J.M. ${ }^{\text {a } ; ~ B E R G A D A ̀, ~ M . M . ; ~ B U R J A C H S, ~ F . ; ~ G a-A R G U ̈ E L L E S, ~ P . ; ~ N A D A L, ~ J . ~ y ~ S O L E R, ~ N . ~}$ (1999): "Le Paléolithique Supérieur méditerranéen ibérique; approches paléoenvironnamentales, industrielles et artistiques", Les faciès leptolithiques du Nord-Ouest méditerranéen: milieux naturels et culturels, actes du XXIV Congrès Préhistorique de France, Carcassonne, septembre 1994, en D. SACCHI, ed. Société Préhistorique Française: 49-78, fig.: 5, tables 3. Carcassonne.

FUMANAL, P. (1997): "Secuencia sedimentoclimática del Pleistoceno Superior Final en el País Valenciano (18000-12000 BP)", en FULLOLA y SOLER (eds.), El mon mediterrani després del pleniglacial (1800012000 BP): 321-327. Girona.

FUMANAL, P. y CARRIÓN, J.S. (1992): "El tránsito del Paleolítico Medio-Superior en la Cova de Beneito (Muro, Alicante). Avance del estudio estratigráfico y sedimentopolínico", en P. UTRILLA (ed.), AragónLitoral Mediterráneo. Intercambios culturales durante la Prehistoria. Zaragoza.

GONZÁLEZ SAINZ, C. (1989): El Magdaleniense Superior-Final de la región cantábrica. Ed. Tantín. Santander.

HEDGES, R. y PETTITT, P. (1998): "On the validity of Archaeological Radiocarbon dates beyond 30.000 years BP", Actes du Colloque C14 et Archéologie: 137-141. Lyon.

HOYOS, M. (1995): "Paleoclimatología del Tardiglacial en la cornisa cantábrica basada en los resultados sediemntológicos de yacimientos arqueológicos kársticos", en MOURE Y GONZÁLEZ (eds.), El Final del Paleolítico Cantábrico: 15-75. Santander. 
ITURBE, G. y CORTELL, E. (1992): "El Musteriense final mediterráneo: nuevas aportaciones”, en P. UTRILLA (ed.), Aragón-Litoral Mediterráneo. Intercambios culturales durante la Prehistoria: 117-127. Zaragoza.

JALUT, G. (1992): "Le paléoenvironnement de la moitié occidentale du versant nord des Pyrenées de 40000 BP à l'actuel: etapes de deglatiation et histoire de la vegetation", The Late Quaternary in the Western Pyrenean region: 125-142. Vitoria.

JIMENO, A.; FERNÁNDEZ, J.J.; GÓMEZ, J.A. y GALINDO, M.P. (1990): “Arte paleolítico en la provincia de Soria", Numantia III: 9-50.

LARTET, L. (1866): "Poteries primitives, instruments en os et sílex taillés des cavernes de la Vieille Castille (Espagne)", Revue Archéologique: 114-134.

LORENZO, J.I. y MONTES, L. (2000): "Restes néandertaliens de la grotte de "Los Moros de Gabasa" (Huesca, Espagne)", Les premiers hommes modernes de la Péninsule Ibérique": 77-86. Vilanova de Foz Coa, Octubre de 1998.

MAROTO, J.; SOLER, N. y FULLOLA, J.M. (1996): "Cultural change between Middle and Upper Palaeolithic in Catalonia", The last neandertals, the first anatomically modern humans: 219-250. Barcelona.

MAZO, C. y UTRILLA, P. (1996): "Excavaciones en la cueva de Abauntz. Campañas de 1994 y 1995", Trabajos de Arqueología Navarra 12: 270-279.

MILLÁN, J.; GARCÍA, J.A. y CEAMANOS, E. (1999): "La Prehistoria en la comarca del Aranda", Catálogo de la Exposición arqueológica del Castilla Palacio de los Luna. Illueca.

MIR, A. (1998): "Un tecnocomplejo arcaico en el contexto del Paleolítico Superior Pirenaico: la cueva de la Fuente del Trucho (Colungo, Huesca)", II Congrés Internacional Història dels Pirineus. Preactas. 1998. Gerona.

MONTES, L.; UTRILLA, P. y HEDGES, R. (2001): "Le passage Paléolithique Moyen-Paléolithique Supérieur dans la Vallée de l'Ebre (Espagne). Datations radiométriques pour les grottes de Peña Miel et Gabasa", en Les premiers hommes modernes de la Péninsule Ibérique: 87-102. Octubre de 1998. Vilanova de Foz Coa.

MONTSERRAT, J.M. (1992): Evolución glaciar y postglaciar del clima y la vegetación en la vertiente Sur del Pirineo: Estudio palinológico. Zaragoza.

MOURE, A. et alii. (1997): "Revisión y nuevos datos sobre el musteriense de la cueva de la Ermita (Hortigüela, Burgos)", II Congreso de Arqueología Peninsular t. I: 67-83.

NUIN, J. (1996): "Investigaciones en el yacimiento del Paleolítico Superior de Legintxiqui (Etxauri, Navarra)", Trabajos de Arqueología Navarra 12: 280 y 281.

PETTITT, P.: "Neanderthal extintion: radiocarbon chronology, problems, prospects and an interpretation of the existing data", Actes du Colloque C14 et Archéologie: 165-170. Lyon.

RINK, W.J.; SCHWARCZ, H.P.; LEE, H.K.; CABRERA, V.; BERNALDO DE QUIRÓS, F. y HOYOS, M. (1996): "ESR Dating of Tooth Enamel: Comparison with 14C at El Castillo Cave, Spain", Journal of Archaeological Science 23: 945-951.

ROSELL, J. et alii. (2000): "El yacimiento de Las Fuentes de San Cristóbal (Veracruz, Huesca): un nuevo enclave del Paleolítico Medio en el Prepirineo", III Congreso de Arqueología Peninsular. Vila Real. vol II: 235-250. Oporto.

SÁNCHEZ GOÑI, F. (1993): De la taphonomie pollinique a la reconstitution de l'environnement. L'exemple de la Région Cantabrique B.A.R. S. 586.

SÁNCHEZ GOÑI, M.F. (1999): "Vegetation et climat sur le pourtour de la Méditerranée au cours du Pléistocène supérieur", XXIV Congrés Préhistorique de France. Les facies leptolithiques du Nordouest méditerranéen: milieux naturels et culturels: 237-250. Carcassonne.

SANTONJA, M. et alii. (2000): "El yacimiento paleolítico de Cuesta de la Bajada(Teruel)", III Congreso de Arqueología Peninsular II: 169-189. Oporto. 
SEBASTIÁN, A. y ZOZAYA, J. (1991): "Informe de la tercera campaña de excavación en El Abrigo de Ángel (Ladruñán, Teruel)”, Arqueología Aragonesa 1988-1989: 53-54.

SEBASTIÁN, A. (1992): "Nuevos datos sobre la cuenca media del río Guadalope: el abrigo del Barranco Hondo y el abrigo de Ángel", Revista Teruel 79 vol. II: 77-92.

TILO, M.A. (1994): "Memoria de la excavación realizada en el Barranco de la Tejería (Monteagudo del Castillo, Teruel) durante la campaña de 1991", Arqueología Aragonesa 17: 59-62. Zaragoza.

UTRILLA, P. (1982): "El yacimiento de la cueva de Abauntz (Arraiz, Navarra)", Trabajos de Arqueología Navarra 3: 203-346. Pamplona.

- (1994): "Campamentos-base, cazaderos y santuarios. Algunos ejemplos del paleolítico peninsular", Homenaje al Dr. Joaquín González Echegaray. MCIA, Monografías 17: 97-113.

— (1995): "El valle del Ebro durante el Tardiglaciar y comienzos del Holoceno. Las relaciones con el Magdaleniense cantábrico", en MOURE y GONZÁLEZ (eds.): El final del Paleolítico Cantábrico. Transformaciones ambientales y culturales durante el Tardiglaciar y comienzos del Holoceno en la Región Cantábrica”: 281-311. Carcassonne.

_ (1997a): "Del Paleolítico al Epipaleolítico. Crónica del Aragón Antiguo. De la Prehistoria a la Alta Edad Media (1987-1993)", Caesaraugusta 72 - I: 15-57.

_ (1997b): "Le couloir de l'Ebre après le Pléniglaciaire: influences méditerranéennes et atlantiques", FULLOLA Y SOLER (eds.) El mon mediterrani després del pleniglacial (18000-12000 BP): 431-442. Girona.

(1997c): "El abrigo de la Peña del Diablo (Cetina, Zaragoza). Campaña de 1994", Arqueología Aragonesa 1994 n ${ }^{\circ}$ 21: 69-74.

UTRILLA, P. y BLASCO, F. (e.p.): "Dos asentamientos magdalenienses en Deza (Soria)", B.S.A.A. Valladolid.

UTRILLA, P. y MAZO, C. (1992): "L'occupation de l'espace dans la grotte d'Abauntz (Navarra, Espagne)", Le Peuplement magdalénien. Chancelade, 1988: 365-376.

_ (1996a): "Non flint raw materials in La Rioja: a tentative interpretation. In Non flint stone tools and the Palaeolithic Occupation of the Iberian Peninsula", British Archaeological Reports 649. Londres. (1996b): "Arte mueble sobre soporte lítico de la cueva de Abauntz. Su aportación a los estilos del Magdaleniense Tardío", Complutum 6: 41-62.

UTRILLA, P. y MONTES, L. (1993): "El final del musteriense en el Valle del Ebro. Datos y reflexiones", El origen del Hombre Moderno en el suroeste de Europa: 219-246. Madrid.

UTRILLA, P.; GONZÁLEZ, P.; FERRER, C. y BLASCO, F. (1999): "La ocupación magdaleniense del valle del río Henar: los asentamientos de Cetina (Zaragoza) y Deza (Soria)", Geologia i Quaternari litoral. Memorial M.P. Fumanal: 283-296.

UTRILLA, P.; LÓPEZ, P. y MAZO, C. (1986): "Interpretación microespacial de una ocupación magdaleniense a través de análisis polínicos y de huellas de uso", Arqueología espacial 8: 41-60. Teruel.

UTRILLA, P.; MONTES, L. y GONZÁLEZ (e.p.): “C'etait l'Ebre une frontière à 40 Ka?", Coloquio The Chronology of the Aurignacian and of the Transitional Technocomplexes. Dating, Stratigraphies, Cultural Implications. XIV Congres de la UISPP, Lieja, Septiembre 2001.

UTRILLA, P.; RIOJA, P. y MAZO, C. (1986): El Paleolítico en La Rioja I. El término de Villar de Torre. Instituto de Estudios Riojanos, Logroño.

UTRILlA, P.; RIOJA, P. y MONTES, L. (1988): El Paleolítico en La Rioja III. El término de Badarán. Monografías Arqueológicas. Zaragoza.

UTRILLA, P.; RIOJA, P. y RODANES, J.Mª (1986): El Paleolítico en La Rioja II. El Término de CañasCirueña. Monografías Arqueológicas. Zaragoza.

UTRILLA, P.; VILCHEZ, J.; MONTES, L.; BARANDIARÁN, I.; ALTUNA, J.; GIL, E. y LÓPEZ, P. (1987): La cueva de Peña Miel. Nieva de Cameros, La Rioja. E.A.E. nº 154. 
UTRILLA, P.; VILLAVERDE, V. y MARTÍNEZ, R. (2001): "Les gravures rupestres de Roca Hernando (Cabra de Mora, Teruel)", Les premiers hommes modernes de la Péninsule Ibérique: 161-174. Octubre de 1998. Vilanova de Foz Coa.

VALLESPÍ, E. (1959): "Bases arqueológicas para el estudio de los talleres de sílex del bajo Aragón. Hacia una seriación de las industrias líticas postpaleolíticas bajoaragonesas", Caesaraugusta 13-14: 7-20.

VALLESPÍ, E. (1961): “Revisión metodológica del problema del Paleolítico del Bajo Aragón”, Caesaraugusta 17-18. Zaragoza.

VALLESPÍ,E. (1975): “Achelense Final y Musteriense en el Alto Valle del Ebro”, Miscelánea arqueológica dedicada al profesor Antonio Beltrán: 1-27. Zaragoza.

VEGA, G. (1993): "La transición del Paleolítico Medio al Paleolítico Superior en el Sur de la Península Ibérica", El origen del Hombre Moderno en el suroeste de Europa: 147-170. Madrid.

VILLAVERDE, V. y FUMANAL, P. (1990): "Relations entre le Paléolithique Moyen et le Paléolithique Supérieur dans le versant méditerranéen espagnol", Paléolithique Moyen récent et Paléolithique Supérieur ancien en Europe: 177-183. Nemours.

VILLAVERDE, V. (1994): Arte Paleolítico de la Cova del Parpalló. Estudio de la colección de plaquetas y cantos grabados y pintados. S.I.P.: 404, figs. 316. Valencia.

VILLAVERDE, V; AURA, E. y BARTON, M. (1998): “The Upper Paleolithic in Mediterranean Spain: A Review of Current Evidence", Journal of World Prehistory 12, 2.

ZILHÃO, J. (1993): "Le passage du Paléolithique moyen au Paléolithique supérieur dans le Portugal", El origen del Hombre Moderno en el suroeste de Europa: 127-145. Madrid. 


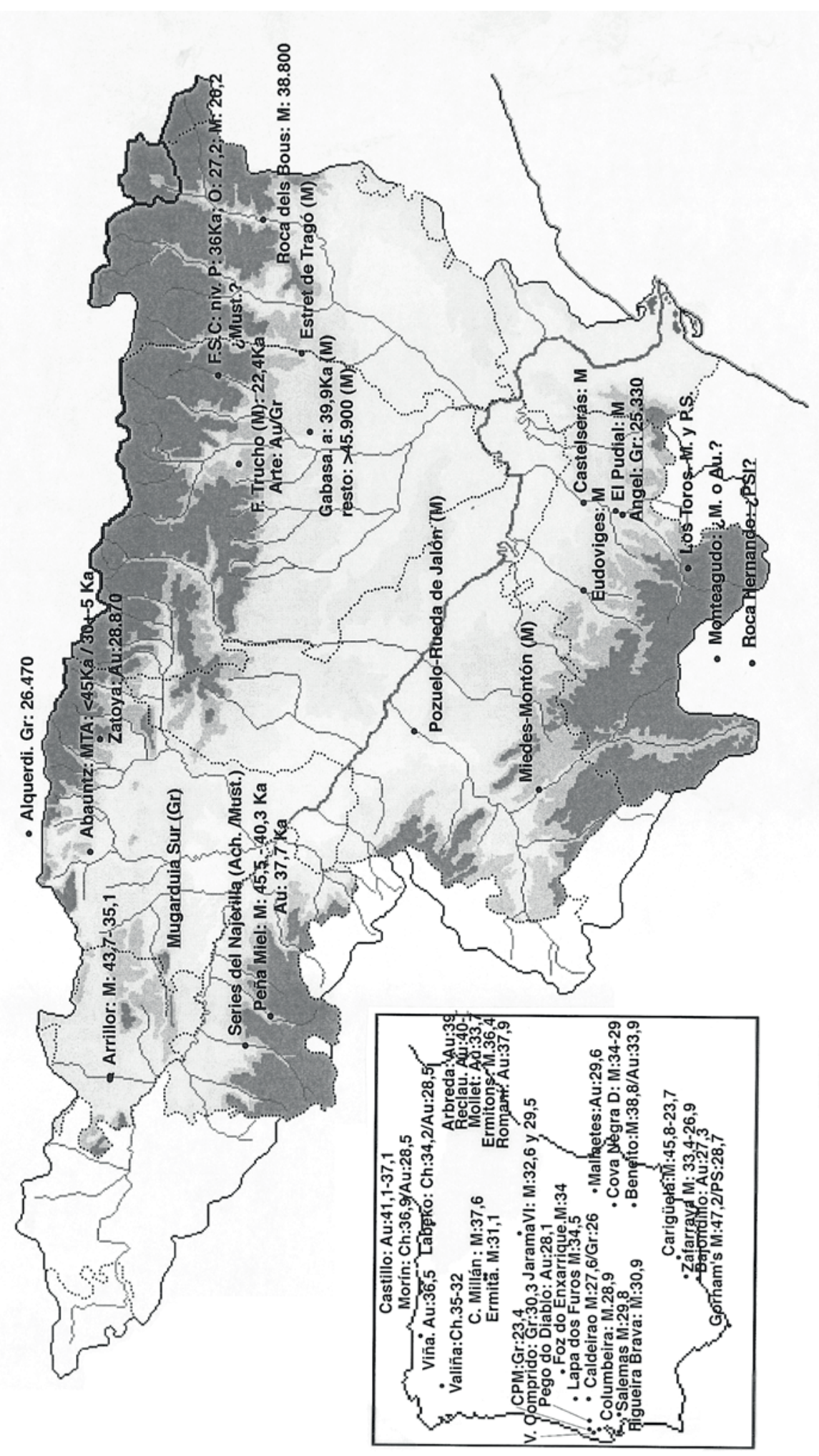

ISSN: 1133-4525 ISSN-e: 2255-3924

SPAL 9 (2000)

http://dx.doi.org/10.12795/spal.2000.i9.04 

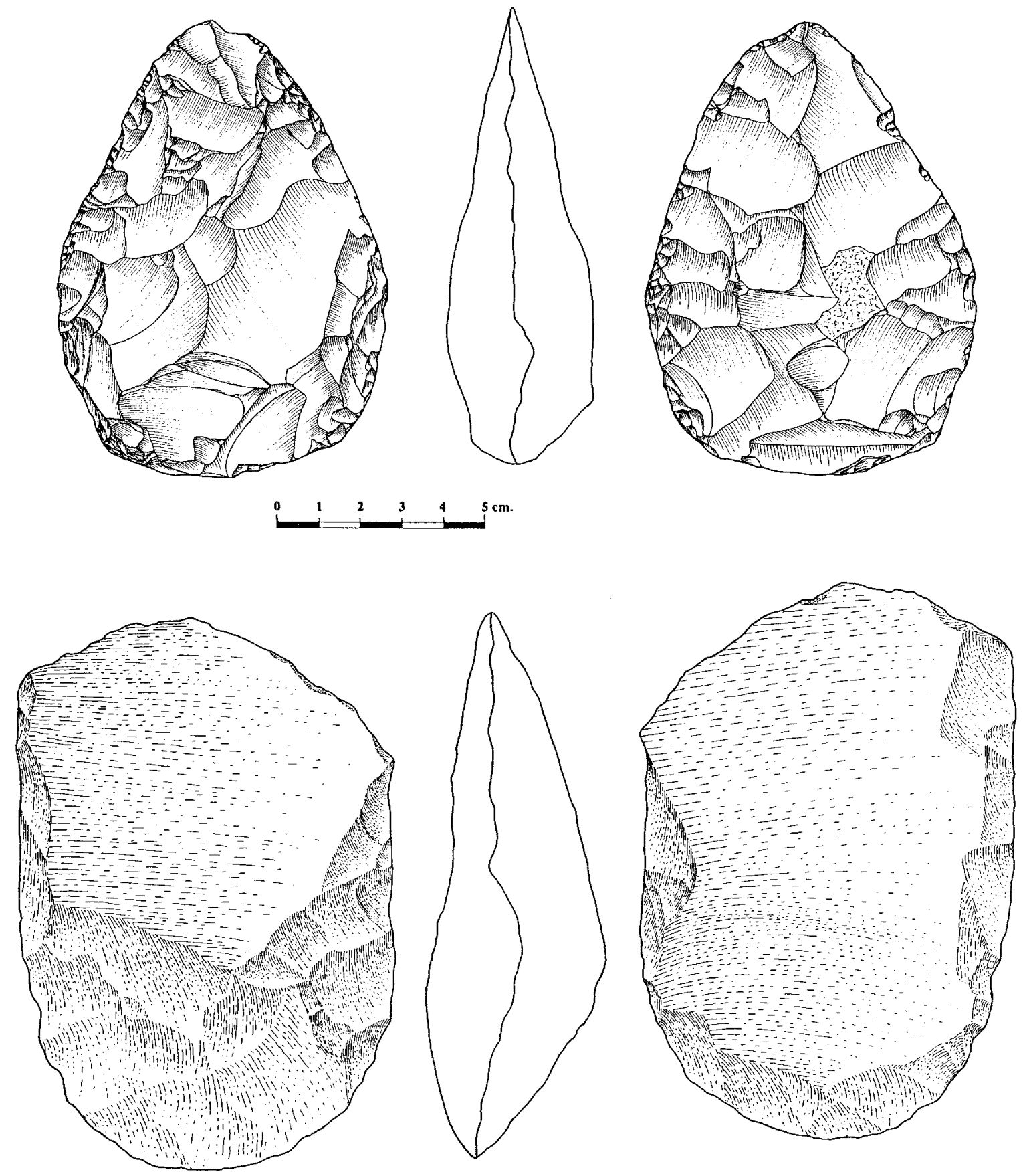

Fig. 2: Bifaz y hendedor del nivel h de Abauntz (M.T.A.) (según Mazo y Utrilla) 


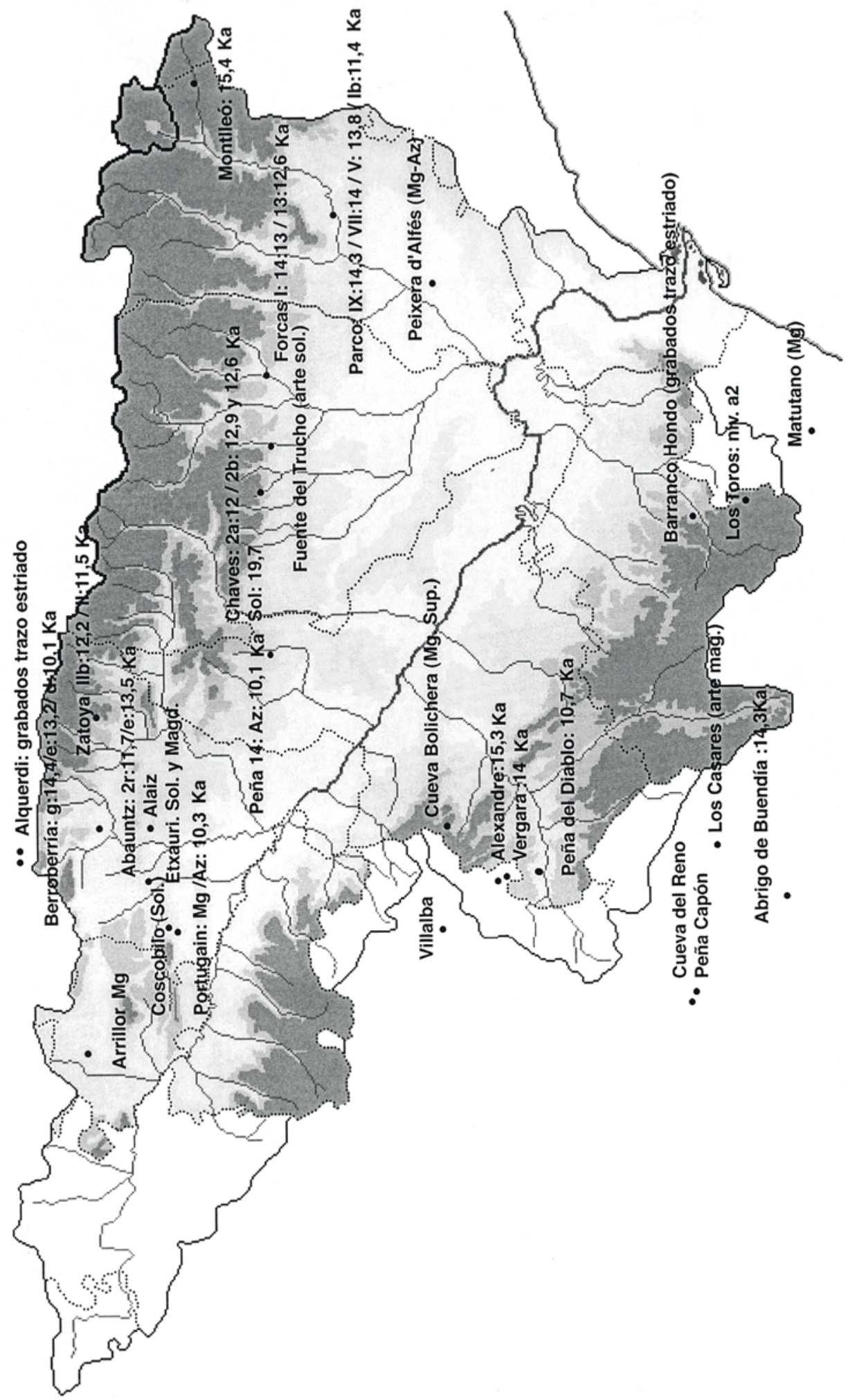

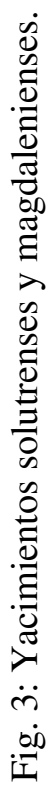

ISSN: 1133-4525 ISSN-e: 2255-3924

SPAL 9 (2000)

http://dx.doi.org/10.12795/spal.2000.i9.04 

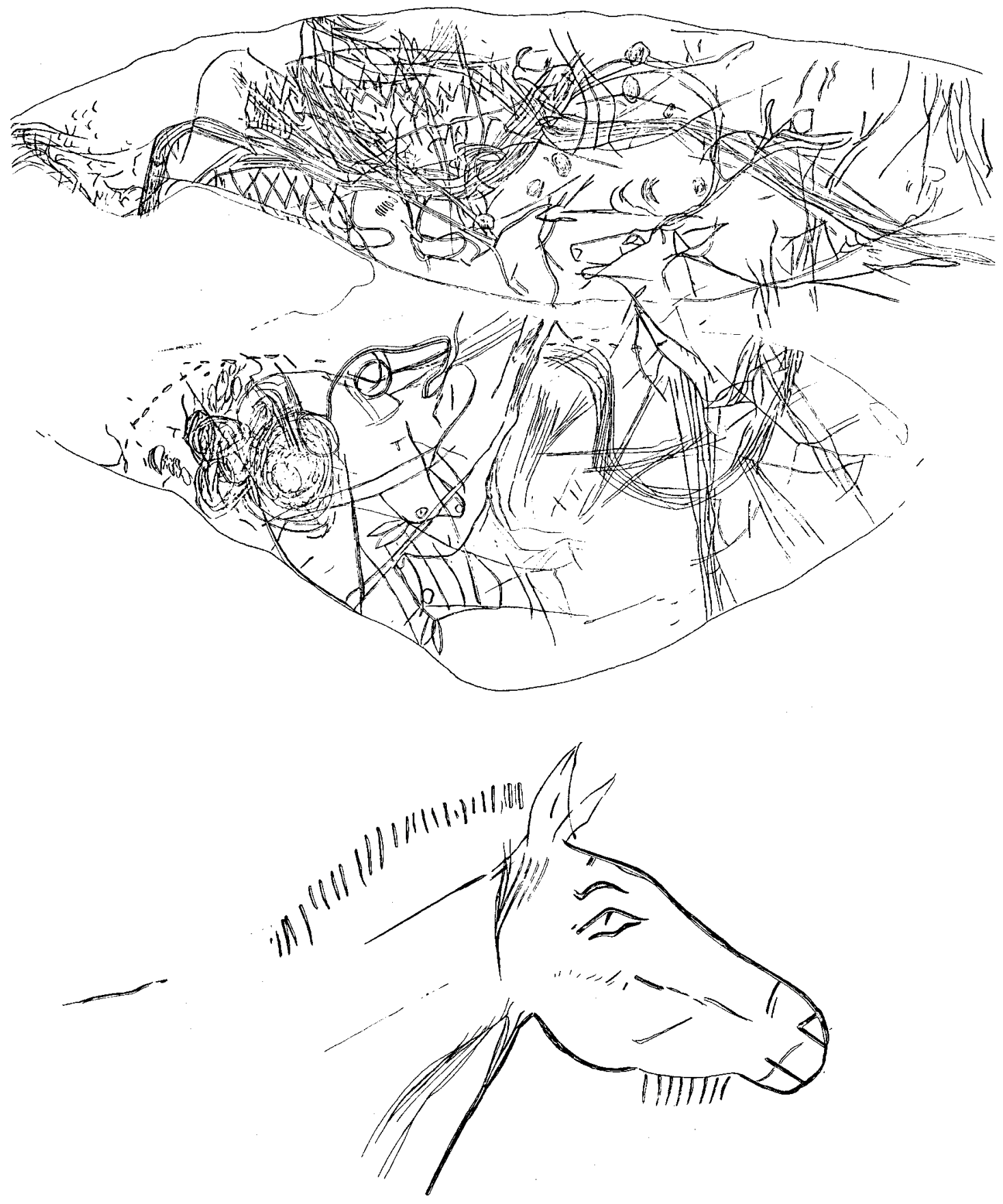

Fig. 4: Nivel 2r (e1) de Abauntz: 11760 BP. Arriba: ciervos, cabras, antropomorfo y terneros (bloque 1). Abajo: caballo del bloque 3. (Según Utrilla y Mazo). 